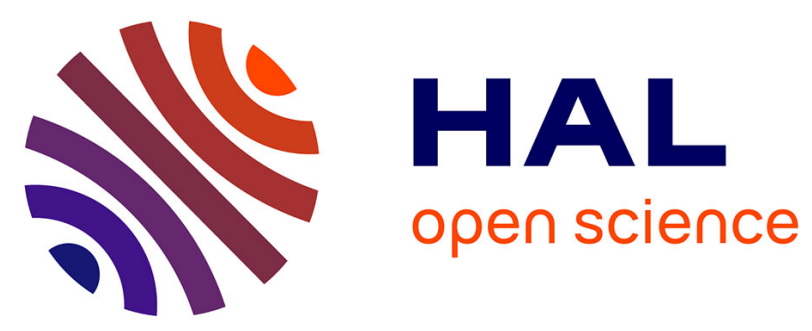

\title{
Azetidinimines as a novel series of non-covalent broad-spectrum inhibitors of $\beta$-lactamases with submicromolar activities against carbapenemases KPC-2 (class A), NDM-1 (class B) and OXA-48 (class D)
}

Eugénie Romero, Saoussen Oueslati, Mohamed Benchekroun, Agathe C.A.

D'hollander, Sandrine Ventre, Kamsana Vijayakumar, Corinne Minard, Cynthia Exilie, Linda Tlili, Pascal Retailleau, et al.

\section{- To cite this version:}

Eugénie Romero, Saoussen Oueslati, Mohamed Benchekroun, Agathe C.A. D'hollander, Sandrine Ventre, et al.. Azetidinimines as a novel series of non-covalent broad-spectrum inhibitors of $\beta$-lactamases with submicromolar activities against carbapenemases KPC-2 (class A), NDM-1 (class B) and OXA48 (class D). European Journal of Medicinal Chemistry, 2021, 219, 10.1016/j.ejmech.2021.113418 . hal-03227989

\section{HAL Id: hal-03227989 \\ https://hal.science/hal-03227989}

Submitted on 17 May 2021

HAL is a multi-disciplinary open access archive for the deposit and dissemination of scientific research documents, whether they are published or not. The documents may come from teaching and research institutions in France or abroad, or from public or private research centers.
L'archive ouverte pluridisciplinaire HAL, est destinée au dépôt et à la diffusion de documents scientifiques de niveau recherche, publiés ou non, émanant des établissements d'enseignement et de recherche français ou étrangers, des laboratoires publics ou privés. 


\section{Azetidinimines as a novel series of non-covalent broad-spectrum inhibitors of $\beta$-lactamases with submicromolar activities against carbapenemases KPC-2 (class A), NDM-1 (class B) and OXA-48 (class \\ D).}

Eugénie Romero, ${ }^{\dagger, \#}$ Saoussen Oueslati, ${ }^{\ddagger,}, \#$ Mohamed Benchekroun, ${ }^{+, \diamond}$ Agathe C. A. D’Hollander, ${ }^{+, 0}$ Sandrine Ventre, ${ }^{\dagger}$ Kamsana Vijayakumar, ${ }^{\dagger}$ Corinne Minard, ${ }^{\dagger}$ Cynthia Exilie, ${ }^{\ddagger}$ Linda Tlili, ${ }^{\ddagger}$ Pascal Retailleau, ${ }^{\dagger}$ Agustin Zavala, ${ }^{\dagger, \neq,}$ Eddy Elisée, ${ }^{\dagger}$ Edithe Selwa, ${ }^{\dagger}$ Laetitia A. Nguyen, ${ }^{\S}$ Alain Pruvost, ${ }^{\S}$ Thierry

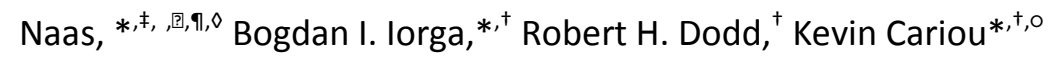

† Université Paris-Saclay, CNRS, Institut de Chimie des Substances Naturelles, LabEx LERMIT, UPR 2301, Gif-sur-Yvette, France.

‡ UMR1184, Inserm, Université Paris-Saclay, LabEx LERMIT, Hôpital Bicêtre, Le Kremlin-Bicêtre, France. Bacteriology-Hygiene Unit, Hôpital Bicêtre, Le Kremlin-Bicêtre, France.

$\S$ Université Paris-Saclay, CEA, INRAE, Département Médicaments et Technologies pour la Santé, Gif-sur-Yvette, France.

[? EERA Unit "Evolution and Ecology of Resistance to Antibiotics Unit, Institut Pasteur-AP-HP-Université Paris-Saclay, Paris, France.

I Associated French National Reference Center for Antibiotic Resistance: Carbapenemase-Producing Enterobacteriaceae, Le Kremlin-Bicêtre, France.

o Current address: Chimie ParisTech, PSL University, CNRS, Institute of Chemistry for Life and Health Sciences, Laboratory for Inorganic Chemical Biology, Paris, France. 


\section{ABSTRACT}

The occurrence of resistances in Gram negative bacteria is steadily increasing to reach extremely worrying levels and one of the main causes of resistance is the massive spread of very efficient $\beta$-lactamases which render most $\beta$-lactam antibiotics useless. Herein, we report the development of a series of imino-analogs of $\beta$-lactams (namely azetidinimines) as efficient non-covalent inhibitors of $\beta$-lactamases. Despite the structural and mechanistic differences between serine- $\beta$-lactamases KPC-2 and OXA-48 and metallo-betalactamase NDM-1, all three enzymes can be inhibited at a submicromolar level by compound 7dfm, which can also repotentiate imipenem against a resistant strain of Escherichia coli expressing NDM-1. We show that $\mathbf{7 d f m}$ can efficiently inhibit not only the three main clinically-relevant carbapenemases of Ambler classes A (KPC-2), B (NDM-1) and D (OXA-48) with Ki's below 0.3 $\mu \mathrm{M}$, but also the cephalosporinase CMY-2 (class C, $86 \%$ inhibition at $10 \mu \mathrm{M}$ ). Our results pave the way for the development of a new structurally original family of non-covalent broad-spectrum inhibitors of $\beta$-lactamases. 


\section{INTRODUCTION}

The discovery of penicillin was the start of a golden age for antibiotic therapy that is now threatened by exponentially increasing antibiotic resistance phenomena.[1] Because $\beta$ lactams (Figure 1a) have been, and still are, the most prescribed antibiotics worldwide, resistance against them is particularly alarming. In Gram negative bacteria (GNB), the main mechanism of $\beta$-lactam resistance is due to the production of $\beta$-lactamases, enzymes capable of hydrolyzing $\beta$-lactams. Even carbapenems, the most powerful $\beta$-lactams, are not spared by metallo- $\beta$-lactamases (MBLs) such as NDM-1, IMP-1 or VIM-1 (class B) and/or by some clinically worrisome serine $\beta$-lactamases (SBLs) such as KPC-2 or OXA-48 (classes A and D, respectively).[2,3] The discovery of novel antibiotics acting on novel targets is difficult to foresee and strategies to overcome $\beta$-lactam resistance[4,5] especially via $\beta$-lactamase inhibition[6-8] may preserve our current therapeutic arsenal. This strategy was implemented more than 30 years ago with the development of $\beta$-lactamase inhibitors (BLIs) including clavulanic acid and sulbactam (Figure 1b), but was not actively pursued until recently. Since 2012 several new broad-spectrum inhibitors of class $A$ and class $C \beta$-lactamases have emerged. Of significant interest, avibactam[9,10] and vaborbactam[11] (Figure 1b) were approved by the FDA for clinical use whilst many of their congeners, in particular diazabicyclooctanes,[12-20] and various boron derivatives (see below), including benzosiloxaboroles,[21] are currently undergoing preclinical or clinical development. These compounds are mainly able to efficiently inhibit SBLs, including carbapenemases, of class $A, C$ and sometimes D, but generally do not inhibit MBLs (class B). In parallel, continuous efforts for the development of efficient MBL inhibitors[22,23] have recently led to the identification of promising molecules that can bind to zinc atoms of the active site of MBLs, such as thiadiazole[24] or thiols[25,26] - including the clinically available antihypertensive agent L- 
captopril[27] -, aspergillomarasmine $A[28]$ and other iminodiacetic acids,[29,30]

rhodanines[31] and their thienolate derivatives[32] or heteroaryl compounds[33,34] such as ANT2681[35] or ANT431[36] (Figure 1c).

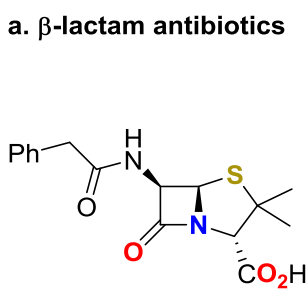

penicillin G, $1943-1945$ penicillin<smiles>CC(C)(ON=C(NC1C(=O)N2C(=O)C(Cn3cccc3)=C([O-])C[SH]12)c1csc(N)n1)C(=O)O</smiles>

ceftazidime, $1983-1987$ cephalosporin<smiles>CC(O)C1C(=O)N2C(C(=O)O)=C(SCCNC=N)CC12</smiles>

imipenem, 1985 - 1998 carbapenem<smiles>CC1C(NC(=O)/C(=N\NC(C)(C)C(=O)O)c2csc(N)n2)C(=O)N1O</smiles>

aztreonam, 1986 monobactam

b. SBL inhibitors<smiles>O=C(O)[C@H]1/C(=C/CO)O[C@@H]2CC(=O)N21</smiles>

clavulanic acid, 1985 clavam<smiles>CC1(C)[C@H](C(=O)O)N2C(=O)C[C@H]2S1(=O)=O</smiles>

sulbactam, 1987 penam

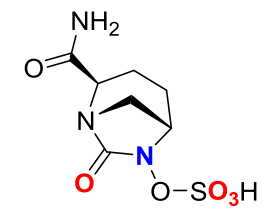

avibactam, 2015 diazabicyclooctanes (DBOs) $\mathrm{IC}_{50}=0.008 \mu \mathrm{M}$ vs. $\mathrm{KPC}-2^{18}$ $\mathrm{IC}_{50}=0.252 \mu \mathrm{M}$ vs. OXA-48 ${ }^{18}$ no activity vs. MBLs

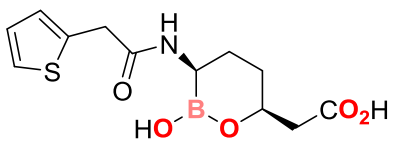

vaborbactam, 2017

boronic acid $\mathrm{Ki}=0.035 \mu \mathrm{M}$ vs. $\mathrm{KPC}-2^{11}$ $\mathrm{IC}_{50}=32 \mu \mathrm{M}$ vs. OXA-48 42 no activity vs.NDM-1

c. MBL inhibitors, $I_{50}$ vs. NDM-1<smiles>[R17][R16](=O)OC(=O)C(C)CS</smiles><smiles>N[C@@H](CN[C@@H](CN[C@H](CC(=O)O)C(=O)O)C(=O)O)C(=O)O</smiles>

aspergillomarasmine $\mathrm{A}$ iminodiacetic acid $\mathrm{IC}_{50}=4.0 \mu \mathrm{M}^{28}$<smiles>CN1CCN(NC(=O)CN2C(=O)/C(=C/c3c(Cl)ccc(Cl)c3Cl)SC2=S)CC1</smiles>

ML302 rhodanine $\mathrm{IC}_{50}=9.44 \mu \mathrm{M}^{32}$

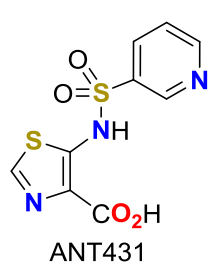

$\mathrm{IC}_{50}=2.67 \mu \mathrm{M}^{36}$

d. dual MBL/SBL inhibitors<smiles>NCCNC1CCC(CC(=O)NC2Cc3ccccc3OP(O)O2)CC1</smiles>

VNRX-5133

boronic acid

$\mathrm{IC}_{50}=0.01 \mu \mathrm{M}$ vs. NDM- $1^{42}$

$\mathrm{IC}_{50}$ vs. KPC-2 not given

$\mathrm{IC}_{50}=2.39 \mu \mathrm{M}$ vs. OXA $-48^{42}$<smiles>C[C@H](CS)C(=O)N[C@@H](Cc1coc2ccccc12)B(O)O</smiles>

MS18

thiol/boronic acid

$\mathrm{IC}_{50}=37.95 \mu \mathrm{M}$ vs. NDM-144

$\mathrm{IC}_{50}=0.61 \mu \mathrm{M}$ vs. KPC-2 $2^{44}$

$\mathrm{IC}_{50}>300 \mu \mathrm{M}$ vs. OXA-48 44<smiles>O=c1cc(CP(=O)(O)O)c2c(Br)cc(Br)cc2[nH]1</smiles>

$\mathrm{Ki}=31.4 \mu \mathrm{M}$ vs. NDM- $1^{39}$

$\mathrm{IC}_{50}=0.02 \mu \mathrm{M}$ vs. KPC-2 $2^{39}$

no activity vs. OXA- $48^{39}$

Figure 1. Representative structures of (a) $\beta$-lactam antibiotics (in bold: year of entry to the market; in italics: year of resistance appearance); (b) serine- $\beta$-lactamase inhibitors (in bold: year of entry to the market) and inhibitory activities of avibactam and vaborbactam activities vs. carbapenemases; (c) metallo- $\beta$-lactamase inhibitors and inhibitory activity vs. NDM-1; (d) dual serine-/metallo- $\beta$-lactamase inhibitors and their representative inhibitory activities vs. carbapenemases. 
Yet there is still no MBL inhibitor available for clinical use. Because of the emergence of bacterial isolates producing two or even three different carbapenemases of different classes, the development of inhibitors capable of simultaneously inhibiting SBLS and MBLs becomes a relevant, yet challenging, strategy. Apart from some polyphenolic derivatives[37] and tetrazoles[38] with moderate activities, only heteroaryl phosphonates[39] and boronic acid derivatives[40-44] have been reported to efficiently inhibit both SBLS and MBLs (Figure 1d). Rigid cyclic analogues of vaborbactam such as VNRX-5133 (currently in phase 3 clinical trials) were the first molecules shown to inhibit all classes of $\beta$-lactamases (Figure 1d).[40-43] VNRX5133 exhibits submicromolar inhibitory activity against several clinically important MBLS (NDM-1, VIM-1 or VIM-2) and SBLS (TEM-116, CMY-2 or OXA-10). Very recently, thiol/boronic acid hybrids (such as MS18) were developed and demonstrated interesting dual inhibition properties against SBLs and MBLs.[44] MS18 and its congeners also possess a rather broad scope but show limited effects against NDM-1 (class B) and OXA-48.

In this context, we sought to develop novel inhibitors that could block the activities of both SBLs and MBLs with comparable efficiency, specifically targeting the three clinically-relevant carbapenemases: KPC-2 (class A), NDM-1 (class B) and OXA-48 (class D).

We addressed this challenge by exploring uncharted chemical space around the $\beta$-lactam nucleus. Synthetically, the $\beta$-lactam ring can be obtained by the Staudinger[45] $[2+2]$ cycloaddition between a ketene and an imine (Scheme 1a).[46] We recently reported that carefully substituted ynamides $[47,48]$ can be used as precursors for the in situ generation of ketenimines $[49,50]$ under mild conditions, which can be intercepted by various heterocyclic nucleophiles[51] or can undergo a microwave-assisted [2+2] cycloaddition with imines.[52] By replacing the ketene $(C=C=O)$ with the in situ generated iminoketene $(C=C=N R)$, the 
reaction directly led to an azetidinimine (Scheme 1b). Such imino- $\beta$-lactams have only been rarely studied with respect to their synthesis[53,54] and never with respect to their biological and particularly, antibiotic activities. Taking into account their structural similarities with $\beta$-lactams, we thus decided to evaluate their inhibitory activity against carbapenemases.
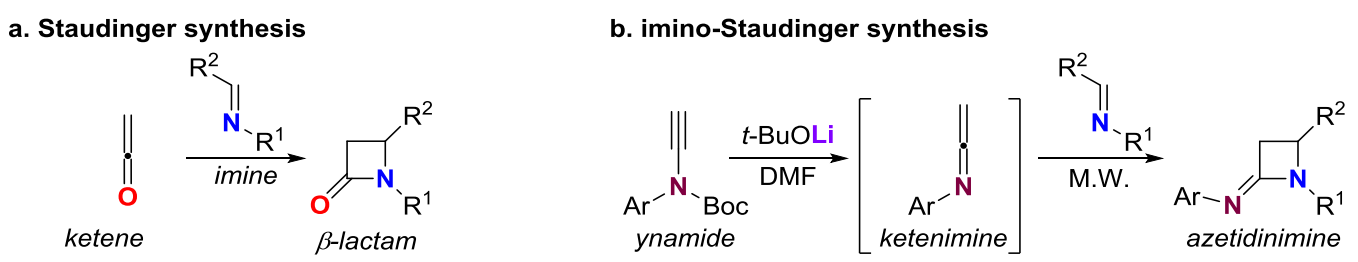

Scheme 1. (a) Staudinger synthesis to access $\beta$-lactams; (b) imino-Staudinger synthesis to access azetidinimines.

\section{RESULTS AND DISCUSSION}

\subsection{Synthesis.}

Taking into consideration the scope of our previously developed methodology and the fact that only aryl groups can be easily incorporated on the imine $\left(\mathrm{Ar}^{1}\right)$ and on positions $1\left(\mathrm{Ar}^{3}\right)$ and $4\left(\mathrm{Ar}^{2}\right)$ of the four-membered-ring,[52] we devised a convergent synthetic plan to access as many structural variations as possible on the azetidinimine scaffold. 


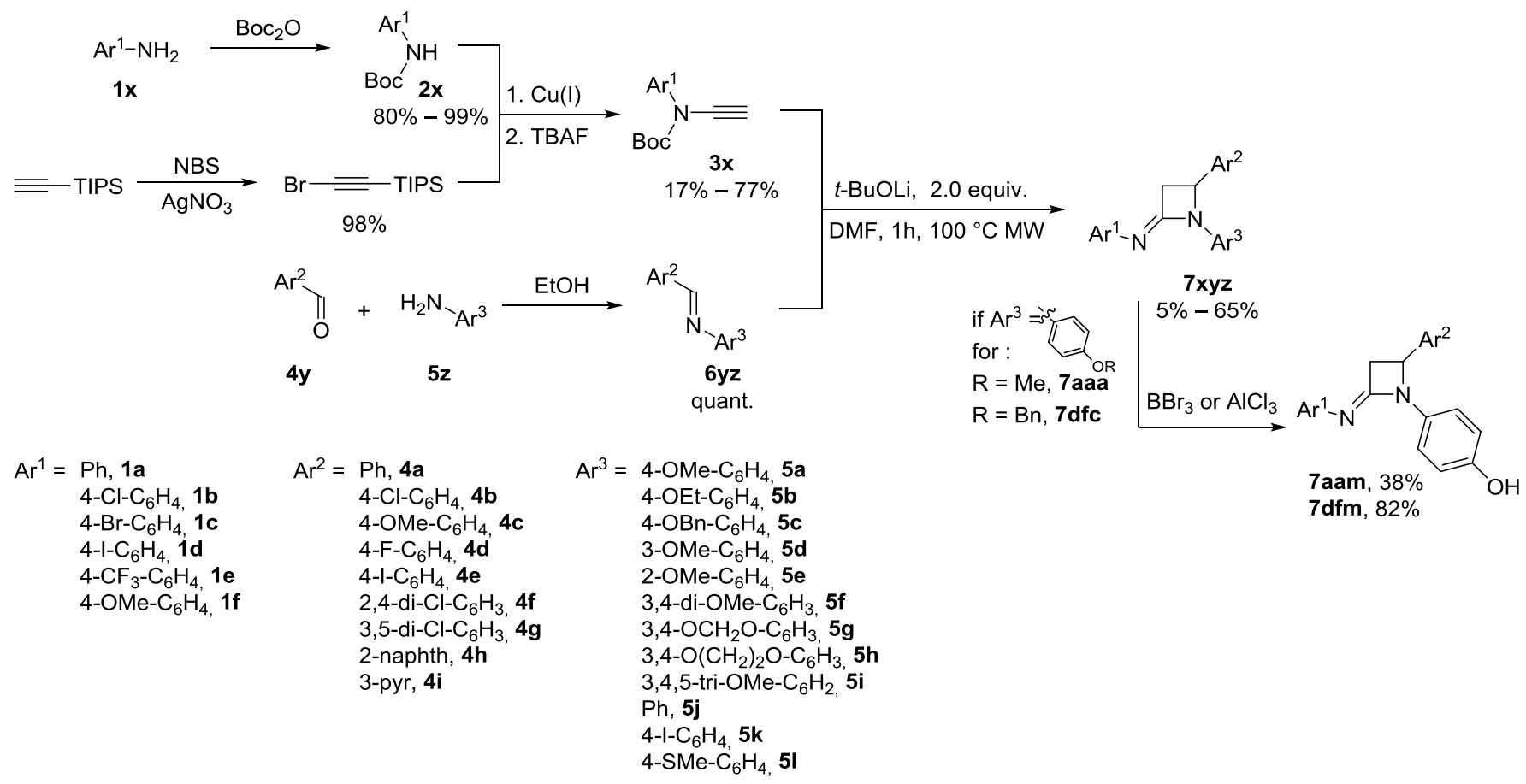

Scheme 2. General synthetic plan to prepare tri-arylated azetidinimines 7xyz.

The $\mathrm{Ar}^{1}$ group originated from aniline $\mathbf{1} \mathbf{x}$, which was protected by a Boc group to give $\mathbf{2 x}$ (Scheme 2). Coupling of $\mathbf{2 x}$ with brominated triisopropylsilylacetylene provided ynamide $\mathbf{3 x}$ after TBAF-promoted desilylation. Condensation of benzaldehyde $\mathbf{4 y}$ with aniline $\mathbf{5 z}$ afforded imines 6yz. The key [2+2] cycloaddition was performed with microwave heating and gave azetidinimines 7xyz with concomitant loss of the Boc protecting group. The para-phenols 7aam, 7abm and 7dfm were obtained from para-alkoxy derivatives 7aaa, 7aba,and 7dfc, respectively, by ether cleavage using $\mathrm{BBr}_{3}$ (for $\mathrm{OMe)}$ or $\mathrm{AlCl}_{3}$ (for $\mathrm{OBn}$ ). Overall, more than forty compounds were prepared using this route.

\subsection{Initial results.}

The first compound evaluated was 7aaa, bearing a $p$-anisyl group on the endocyclic nitrogen. This aryl group was initially chosen for synthetic reasons as it should electronically favor the reaction and could also be easily derivatized. In the presence of $10 \mu \mathrm{M}$ of 7aaa, the hydrolysis of imipenem by NDM-1 was inhibited by $90 \%$ with a $K_{i}$ between 1.0 and $2.4 \mu \mathrm{M}$ 
(Table 1). This very encouraging initial result prompted us to try and gain more insights about this inhibitory activity by performing in silico molecular modeling studies (Figure 2). It appeared that the azetidinimine does not seem to behave like a $\beta$-lactam during metallo beta-lactamase catalyzed hydrolysis, in which case the carbonyl group is chelated by the zinc ions during the hydrolysis process.[22] Here, the methoxy group of 7aaa, rather than the imino moiety, would be coordinated by both zinc ions in the active site and the fourmembered ring would act as a scaffold to position the two phenyl rings in hydrophobic regions of the enzyme active site.

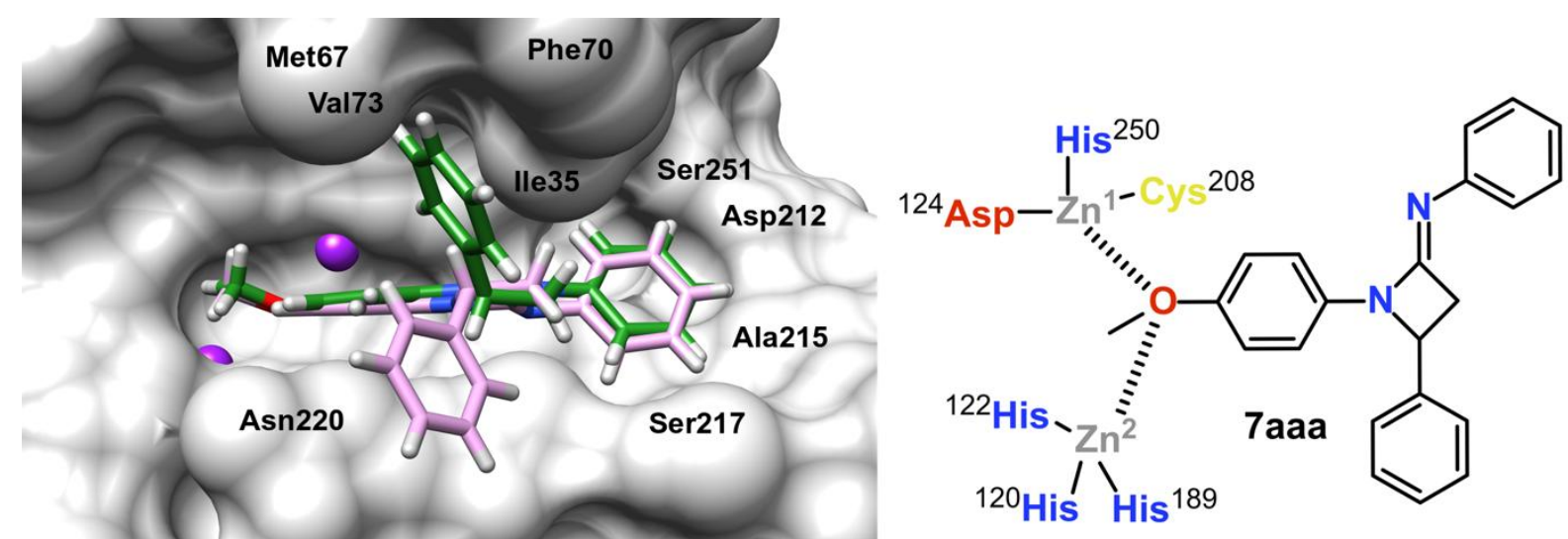

Figure 2. Docking of compound 7aaa in the active site of NDM-1 (left) and schematic drawing of its key interactions with the zinc ions (right). The $R$ and $S$ enantiomers of 7aaa are colored in pink and green, respectively, and the zinc ions are colored in purple.

The $\mathrm{Ar}^{1}$ phenyl substituent is surrounded by Ser251, Asp212, Ala 215 and Ser217 for both enantiomers, whereas the $\mathrm{Ar}^{2}$ phenyl substituent is positioned near Asn220 in the $R$ enantiomer and in the proximity of Val73, Ile 35, Met67 and Phe70 in the $S$ enantiomer (Figure 2). The two enantiomers of 7aaa were separated by chiral chromatography and each tested separately. Both enantiomers showed similar inhibition of NDM-1 (95\% inhibition of NDM-1 at $10 \mu \mathrm{M}$, with an $\mathrm{IC}_{50}$ estimated below $\left.5 \mu \mathrm{M}\right)$ that correlates with the racemic mixture activity.

\subsection{SAR for enzyme inhibitory activities.}


A systematic structure-activity relationship study was then undertaken by varying the aromatic groups around the azetidinimine nucleus and targeting three carbapenemases: NDM-1, OXA-48 and KPC-2. Preliminary assessment of the compound activities was carried out by first measuring their inhibitory potential at $10 \mu \mathrm{M}$. When the inhibition was lower than $50 \%$ at this threshold concentration, the $K_{i}$ was not determined. In addition to its NDM1 inhibitory activity, 7aaa was also found to be moderately active against KPC-2 but did not have any activity against OXA-48 (Table 1). Variations of the $\mathrm{Ar}^{3}$ ring showed that minimal modifications such as replacing the methoxy of 7aaa by an ethoxy (7aab) or a benzyloxy (7aac) led to an improvement of the activity against all three enzymes, 7aac in particular displaying a sub-micromolar activity against NDM-1 $\left(K_{i}=0.2 \mu \mathrm{M}\right)$. An activity profile similar to 7aab and 7aac was observed when the methoxy group was in the meta position (7aad). However, the presence of two methoxy groups (7aaf), or a benzo[d][1,3]dioxole moiety (7aag), led to a slight decrease of efficiency against NDM-1 and a loss of activity for OXA-48 and KPC-2. This was partially restored by incorporation of a 2,3-dihydrobenzo[b][1,4]dioxane, as 7aah was found to be quite similar to 7aad in terms of inhibition profile. While the 3,4,5-trimethoxy derivative 7aai proved ineffective (which could also be due to its low solubility), aniline-derived compound 7aaj was found to inhibit all three enzymes with $K_{i}^{\prime}$ s of $4.62,0.8$ and $2.41 \mu \mathrm{M}$, for NDM-1, OXA-48 and KPC-2 respectively. The incorporation of an iodine atom (7aak) on the para position led to solubility issues preventing data from being obtained for OXA-48 and KPC-2 although the anti NDM-1 activity could nevertheless be evaluated to be in the 4.0-5.0 $\mu \mathrm{M}$ range. The thiomethyl derivative 7aal was also poorly soluble in water, but a high inhibition of NDM-1 could still be estimated $\left(K_{i}<0.5 \mu \mathrm{M}\right)$, which is presumed to come from the strong affinity of the sulfur for the active site $\mathrm{Zn}$ ions. Finally, the free phenol 7aam was moderately active 
against KPC-2 and OXA-48 but again exhibited high inhibitory properties against NDM-1 ( $K_{i}=$ $0.36 \mu \mathrm{M})$. To conclude in this series of $\mathrm{Ar}^{3}$ variations, the carbapenemase inhibitors that appeared the most promising (strong anti NDM-1 activity and moderate activity vs. OXA-48 and KPC-2) were $p$-oxyphenyl compounds and especially those bearing a benzyloxy (7aac) and a free hydroxy (7aam) group. 
Table 1. Influence of $\mathrm{Ar}^{3}$ on NDM-1, OXA-48 and KPC-2 inhibitory activities compared to 7aaa.

\begin{tabular}{|c|c|c|c|}
\hline \multirow[b]{2}{*}{ Compound } & \multicolumn{3}{|c|}{$\boldsymbol{K}_{i}(\boldsymbol{\mu M})$ or $\%$ inhibition $^{a}$} \\
\hline & NDM-1 & OXA-48 & KPC-2 \\
\hline & $1.0-2.4^{b}$ & N.E. & $3.6-5-2^{b}$ \\
\hline $7 a a b$ & $1.0-2.4^{b}$ & $\begin{array}{c}45 \% \text { inhibition } \\
\text { at } 10 \mu \mathrm{M}\end{array}$ & $1.4-3.6^{\mathrm{b}}$ \\
\hline & $0.20 \pm 0.01$ & $\begin{array}{c}31 \% \text { inhibition } \\
\text { at } 10 \mu \mathrm{M}\end{array}$ & $1.15 \pm 0.07$ \\
\hline $7 \mathrm{aad}$ & $0.65 \pm 0.07^{c}$ & $\begin{array}{c}28 \% \text { inhibition } \\
\text { at } 10 \mu \mathrm{M}\end{array}$ & $3.6-7.2^{b, c}$ \\
\hline 7aaf & $2.4-4.9^{b, c}$ & N.E & N.E \\
\hline 7 aag & $2.39 \pm 0.29^{c}$ & N.E & N.E \\
\hline 7 aah & $0.73 \pm 0.05^{c}$ & $\begin{array}{c}37 \% \text { inhibition } \\
\text { at } 10 \mu M^{c}\end{array}$ & $3.6-7.2^{b, c}$ \\
\hline 7aai & N.E. & N.E. & N.E. \\
\hline & $4.62 \pm 0.22$ & $0.8 \pm 0.06$ & $2.41 \pm 0.23$ \\
\hline 7aak & $1.9-2.4^{b}$ & N.D. & N.D. \\
\hline & $<0.5^{b}$ & N.E & $\begin{array}{c}50 \% \text { inhibition at } 10 \\
\mu \mathrm{M}\end{array}$ \\
\hline 7aar & $0.36 \pm 0.03$ & $\begin{array}{c}26 \% \text { inhibition at } 10 \\
\mu \mathrm{M}\end{array}$ & $\begin{array}{c}45 \% \text { inhibition at } 10 \\
\mu M\end{array}$ \\
\hline
\end{tabular}

N.E.: no effect (at $10 \mu \mathrm{M}$ ); N. D.: not determined; ${ }^{a} K_{i}$ values were calculated only for inhibitions $>50 \%$ at $10 \mu \mathrm{M}$. ${ }^{b}$ because of some solubility issues (presence of precipitate during the assay) the $K_{i}$ values were not averaged so a range is given instead. ${ }^{c}$ the compound was contaminated by residues of Color code: $\begin{array}{llll}K_{i}<0.5 \mu \mathrm{M} & K_{i}<1.0 \mu \mathrm{M} & K_{i}<10 \mu \mathrm{M} & \mathrm{IC}_{50}>10 \mu \mathrm{M} \\ \end{array}$ 
Table 2. Influence of $\mathrm{Ar}^{2}$ on NDM-1, OXA-48 and KPC-2 inhibitory activities compared to 7aaa.

\begin{tabular}{lll} 
& \multicolumn{3}{c}{ K $(\mu \mathrm{M})$ or $\%$ inhibition $^{a}$} \\
\hline
\end{tabular}

N.E.: no effect (at $10 \mu \mathrm{M}$ ); N. D.: not determined; ${ }^{a} K_{i}$ values were calculated only for inhibitions $>50 \%$ at $10 \mu \mathrm{M}$. ${ }^{\text {b }}$ because of some solubility issues (presence of precipitate during the assay) the $K_{i}$ values were not averaged so a range is given instead. ${ }^{c}$ the compound was contaminated by residues of heptane.

Color code: $\quad K_{i}<0.5 \mu \mathrm{M} \quad K_{i}<1.0 \mu \mathrm{M} \quad K_{i}<10 \mu \mathrm{M} \quad \mathrm{IC}_{50}>10 \mu \mathrm{M}$

Keeping a para-methoxyphenyl group as $\mathrm{Ar}^{3}$, variations of $\mathrm{Ar}^{2}$ were then examined for activity and compared to 7aaa (Table 2). The $p$-chloro analogue (7aba) maintained a similar activity against NDM-1 although the anti-OXA-48 or anti-KPC-2 effects were largely lost. Both $p$-methoxy and p-fluoro analogues 7aca and 7ada were mostly inefficient on all three enzymes while the $p$-iodo, 3,5-dichloro and 2-naphthyl derivatives (7aea, 7aga and 7aha respectively) presented an interesting profile, being almost equipotent against NDM-1 and 
KPC-2 but somewhat less effective against OXA-48. In contrast, pyridinyl compound 7aia was inactive on all three enzymes.

From these results, two $\mathrm{Ar}^{2}$ groups were selected: para-chloro and 2-naphthyl (as in 7aba and 7aha). At this stage, we wished to evaluate the influence of $\mathrm{Ar}^{1}$ in both series (4-chloro in Table 3 and 2-naphthyl in Table 4).

Table 3. Influence of $\mathrm{Ar}^{1}$ on NDM-1, OXA-48 and KPC-2 inhibitory activities compared to 7aba and $7 \mathrm{cfa}$.

\begin{tabular}{|c|c|c|c|}
\hline \multirow[b]{2}{*}{ Compound } & \multicolumn{3}{|c|}{$\boldsymbol{\kappa}_{i}(\boldsymbol{\mu} \mathrm{M})$ or $\%$ inhibition $^{a}$} \\
\hline & NDM-1 & OXA-48 & KPC-2 \\
\hline & $1.0-2.4^{b}$ & N.E & N.E \\
\hline & $0.24 \pm 0.02$ & $\begin{array}{c}27 \% \text { inhibition } \\
\text { at } 10 \mu \mathrm{M}\end{array}$ & $1.93 \pm 0.14$ \\
\hline $7 \mathrm{cba}$ & $0.3 \pm 0.06$ & $0.84 \pm 0.04$ & $1.55 \pm 0.18$ \\
\hline 10 & $0.33 \pm 0.02$ & $0.83 \pm 0.02$ & $1.81 \pm 0.11$ \\
\hline & $0.32 \pm 0.02$ & $\begin{array}{c}32 \% \text { inhibition } \\
\text { at } 10 \mu \mathrm{M}\end{array}$ & $2.36 \pm 0.21$ \\
\hline da & $0.86 \pm 0.07$ & $\begin{array}{c}31 \% \text { inhibition } \\
\text { at } 10 \mu \mathrm{M}\end{array}$ & N.E. \\
\hline & $0.58 \pm 0.04$ & $\begin{array}{c}46 \% \text { inhibition } \\
\text { at } 10 \mu \mathrm{M}\end{array}$ & $\begin{array}{c}30 \% \text { inhibition } \\
\text { at } 10 \mu \mathrm{M}\end{array}$ \\
\hline $7 \mathrm{dfa}$ & $0.24 \pm 0.02$ & $0.93 \pm 0.04$ & $1.89 \pm 0.17$ \\
\hline 7efa & $0.37 \pm 0.02$ & $0.64 \pm 0.04$ & $6.04 \pm 0.27$ \\
\hline
\end{tabular}

N.E.: no effect (at $10 \mu \mathrm{M}$ ) ; ${ }^{\text {a }} \mathrm{Ki}$ values were calculated only for inhibitions $>50 \%$ at $10 \mu \mathrm{M}$. ${ }^{\mathrm{b}}$ because of some solubility issues (presence of precipitate during the assay) the $K_{i}$ values were not averaged so a range is given instead. Color code: \begin{tabular}{lllll}
$K_{i}<0.5 \mu \mathrm{M}$ & $K_{i}<1.0 \mu \mathrm{M}$ & $K_{i}<10 \mu \mathrm{M}$ & $\mathrm{IC}$ & $\mathrm{C}_{50}>10 \mu \mathrm{M}$ \\
\hline
\end{tabular} 
It is worth noting that 4-chloro derivatives generally exhibit a greater ease of synthesis due to the superior reactivity of imine $\mathbf{6 b z}$ (or $\mathbf{6 f z}$ ) in the [2+2] cycloaddition. Compared to 7aba, the introduction of a substituent at the para position of $\mathrm{Ar}^{1}$ - whether a chloro (7bba), a bromo (7cba), an iodo (7dba), a trifluoromethyl (7eba) and to a lesser extent a methoxy group (7fba) - was highly beneficial for the anti-NDM-1 activity, with all compounds possessing $K_{i}$ values in the $0.24-0.33 \mu \mathrm{M}$ range (Table 3 ).

Table 4. Influence of $\mathrm{Ar}^{1}$ on NDM-1, OXA-48 and KPC-2 inhibitory activities compared to 7aha and 7ahb.

\begin{tabular}{|c|c|c|c|}
\hline \multirow[b]{2}{*}{ Compound } & \multicolumn{3}{|c|}{$\boldsymbol{K}_{i}(\boldsymbol{\mu M})$ or $\%$ inhibition $^{a}$} \\
\hline & NDM-1 & OXA-48 & KPC-2 \\
\hline & $1.0-2.4^{b}$ & $1.2-2.3^{b}$ & $3.6-5.0^{b}$ \\
\hline bha & $0.73 \pm 0.08$ & $\begin{array}{c}18 \% \text { inhibition } \\
\text { at } 10 \mu \mathrm{M}\end{array}$ & $3.94 \pm 0.25$ \\
\hline cha & $0.52 \pm 0.03$ & $0.39 \pm 0.04$ & $5.23 \pm 0.25$ \\
\hline Iha & $0.23 \pm 0.02$ & $0.85 \pm 0.04$ & $1.58 \pm 0.12$ \\
\hline & $2.4-3.4^{b}$ & N.D. & N.D. \\
\hline bhb & $0.27 \pm 0.03$ & $\begin{array}{c}30 \% \text { inhibition } \\
\text { at } 10 \mu \mathrm{M}\end{array}$ & $1.96 \pm 0.08$ \\
\hline dhb & $0.25 \pm 0.02$ & $0.70 \pm 0.02$ & $1.84 \pm 0.08$ \\
\hline $\mathrm{fhb}^{\mathrm{MeC}}$ & $0.27 \pm 0.03$ & $0.84 \pm 0.02$ & $1.81 \pm 0.16$ \\
\hline
\end{tabular}

N. D.: not determined; ${ }^{a} K_{i}$ values were calculated only for inhibitions $>50 \%$ at $10 \mu \mathrm{M}$. ${ }^{\mathrm{b}}$ because of some solubility issues (presence of precipitate during the assay) the $K_{i}$ values were not averaged so a range is given instead. $\quad$ Color code: $K_{i}<0.5 \mu \mathrm{M} \quad K_{i}<1.0 \mu \mathrm{M} \quad K_{i}<10 \mu \mathrm{M} \quad \mathrm{IC}_{50}>10 \mu \mathrm{M}$ 
The $K_{i}^{\prime}$ s for KPC-2 were also improved with values between 1.55 and $2.36 \mu \mathrm{M}$, except for 7fba. Additionally, the $K_{i}^{\prime}$ 's against OXA-48 dropped under the $1.0 \mu \mathrm{M}$ threshold for two compounds (7cba and 7dba). A similar trend could be observed with an additional chloro at the 2 position of $\operatorname{Ar}^{2}$ (2,4-dichloro series): the para-iodo (7dfa) and para-trifluoromethyl (7efa) derivatives were found to be the most potent pan-inhibitors of carbapenemases NDM-1, OXA-48 and KPC-2 in this series. Similarly, excellent anti-NDM-1 activities were observed in the $\mathrm{Ar}^{2}$ = naphthyl series (Table 4), with four compounds (7dha, 7bhb, 7dhb and 7fhb) having $K_{i}^{\prime}$ s below $0.3 \mu \mathrm{M}$. Activities against KPC-2 and OXA-48 were also significantly improved, with $K_{i}^{\prime}$ s always being under or close to $5.0 \mu \mathrm{M}$, except in the case of parachlorinated derivatives 7 bha and 7 bhb for OXA-48 inhibition. Despite their high activity, the increased lipophilicity brought by the naphthyl group (for $\mathbf{7 d h b} \log P_{\text {theor }}=6.94$ ) caused products in this series to be very poorly soluble and to easily form aggregates in the assay media. Further studies of this series were thus discontinued.

Having witnessed the highly favorable effect of the para-iodo substitution on $\mathrm{Ar}^{1}$ and keeping in mind the importance of the para-alkoxy moiety on $\mathrm{Ar}^{3}$, further study of the influence of $\mathrm{Ar}^{2}$ was carried out with 7dba as reference (Table 5). All compounds in this series bearing a para-methoxy moiety on $\mathrm{Ar}^{3}$ (first 6 entries) offered a rather broadspectrum of activity, most inhibiting all carbapenemases, with $K_{i}^{\prime}$ s below $10 \mu \mathrm{M}$ and even submicromolar for NDM-1 and OXA-48. Finally, keeping $\mathrm{Ar}^{1}=p$-iodophenyl and $\mathrm{Ar}^{2}=2,4-$ dichlorophenyl (7dfa), variations on $\mathrm{Ar}^{3}$ were then further investigated. Surprisingly (compared with 7aaa and 7aac in Table 1), the $p$-benzyloxyphenyl derivative (7dfc) proved to be slightly less active than 7dfa (Table 5). Compound 7dfc was then converted into a free phenol (7dfm) by $\mathrm{AlCl}_{3}$-mediated cleavage of the ether bond (see Scheme 3). This compound 
exhibited submicromolar $K_{i}^{\prime}$ s for the three enzymes: $0.07 \mu \mathrm{M}$ for NDM-1 and OXA-48 and $0.28 \mu \mathrm{M}$ for KPC-2.

Table 5. Influence of $\mathrm{Ar}^{2}$ compared to 7dba and of $\mathrm{Ar}^{3}$ compared to 7dfa on NDM-1, OXA-48 and KPC-2 inhibitory activities

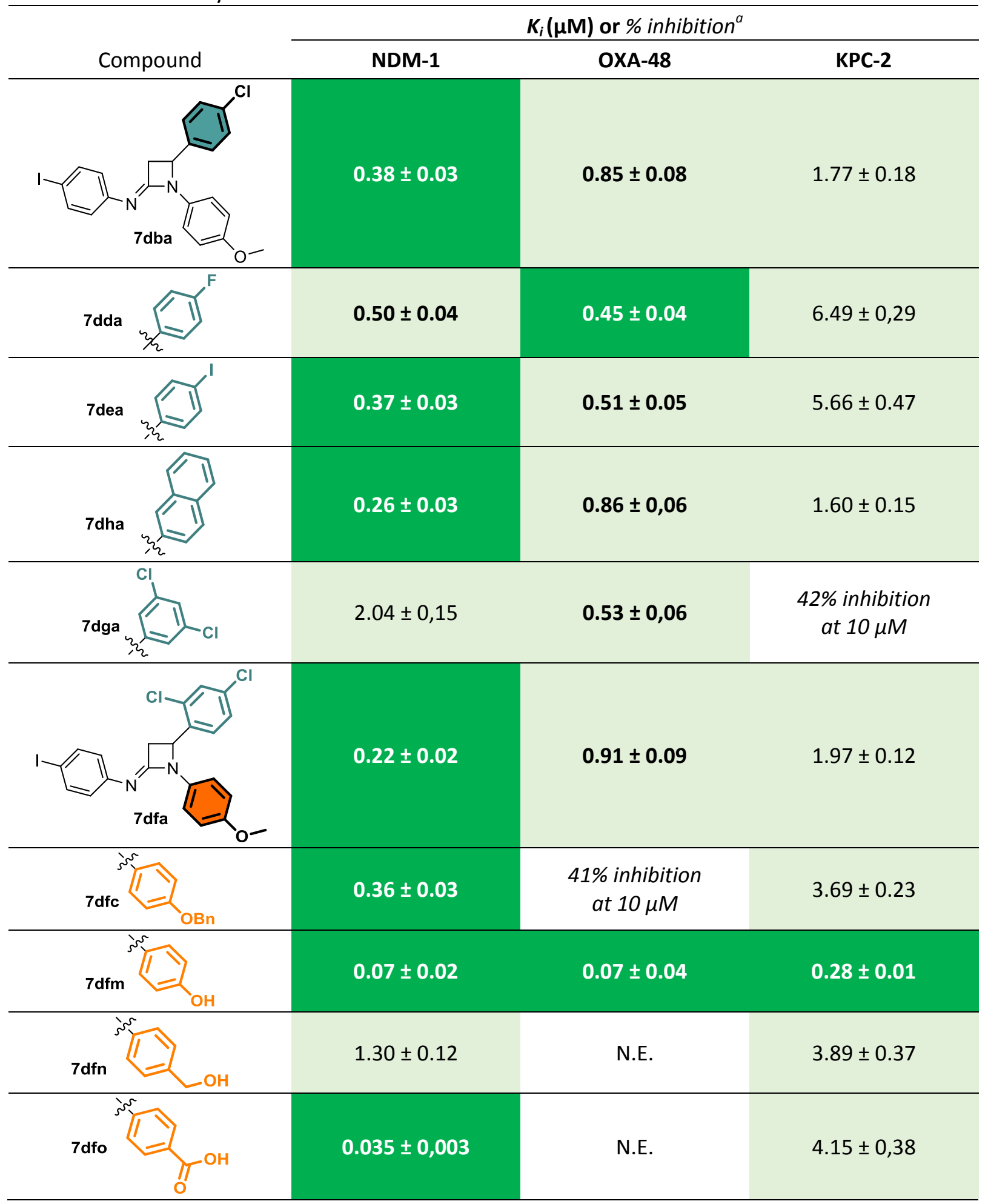

N.E.: no effect (at $10 \mu \mathrm{M}$ ); N. D.: not determined; ${ }^{a} K_{i}$ values were calculated only for inhibitions $>50 \%$ at

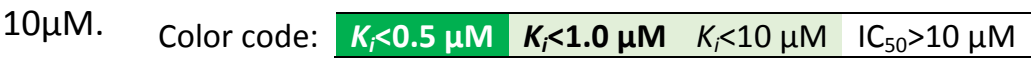


While the homologous benzylic alcohol analogue 7dfn was found to be less active, the corresponding carboxylic acid $\mathbf{7 d f o}$ (obtained by oxidation of $\mathbf{7 d f n}$ with $\mathrm{KMnO}_{4}$, see Scheme 3) was the most active compound on NDM-1 (which could be explained by strong interactions of the carboxylate function with the zinc ions of the active site) in this series with a $K_{i}$ of $0.035 \mu \mathrm{M}$, albeit at the expense of a complete loss of activity against OXA-48.

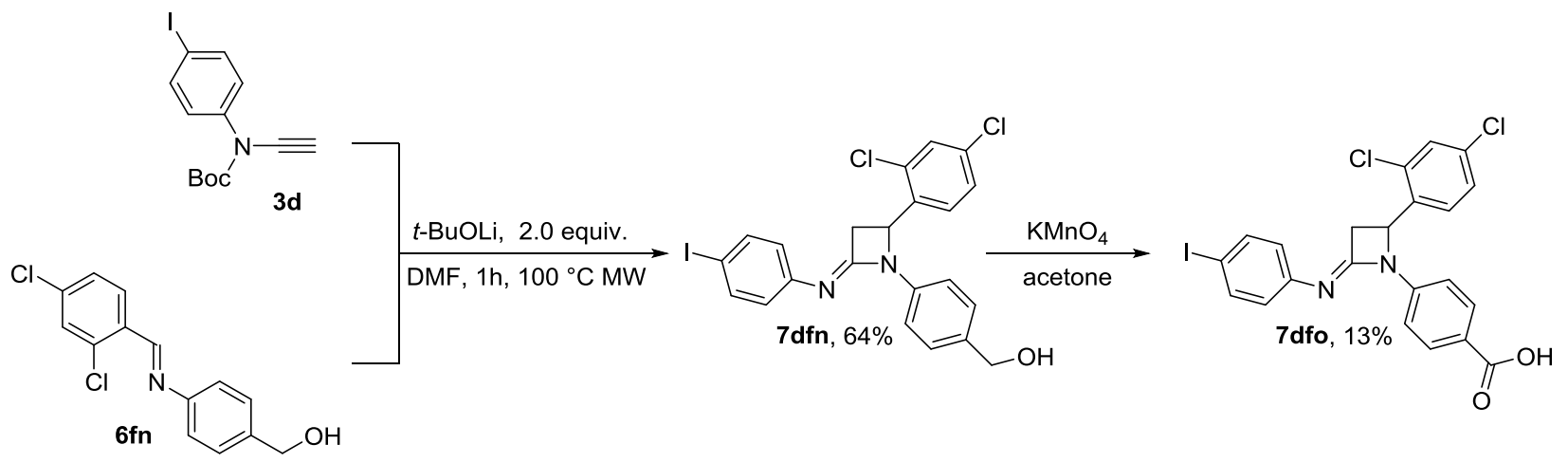

Scheme 3. Synthesis of compounds $\mathbf{7 d f n}$ and $\mathbf{7 d f o . ~}$

\subsection{Complementary assays.}

Having found a lead (7dfm) in our novel azetidinimine BLI series, we then performed complementary assays to more accurately assess its therapeutic potential. First, it was screened at $10 \mu \mathrm{M}$ against a wider panel of BLs (Table 6). At this concentration a complete inhibition of three NDM variants (NDM-4, NDM-7 and NDM-9) and of VIM-1 (class B) was observed. In contrast, VIM-52 (a His224Arg variant of VIM-1,[55] class B) was not affected. The extended-spectrum $\beta$-lactamase CTX-M-15 (class A) and the cephalosporinase CMY-2 (class C) were also inhibited ( $83 \%$ and $86 \%$, at $10 \mu \mathrm{M}$, respectively). These latter results demonstrate that compound $\mathbf{7 d f m}$ can inhibit not only carbapenemases from 3 classes but, more generally, BLs from all four classes.

Table 6. Additional enzymatic inhibitory activities (\% at $10 \mu \mathrm{M})$ for $\mathbf{7 d f m}$

\begin{tabular}{llllllll}
\hline Compound & NDM-4 & NDM-7 & NDM-9 & VIM-1 & VIM-52 & CTX-M-15 & CMY-2 \\
\hline
\end{tabular}




\begin{tabular}{l|l|l|l|l|l|l|l|}
\hline $7 \mathrm{dfm}$ & $100 \%$ & $100 \%$ & $100 \%$ & $100 \%$ & $0 \%$ & $83 \%$ & $86 \%$ \\
\hline
\end{tabular}

In view of future in vivo assays, the phase I metabolic stability of $\mathbf{7 d f a , ~} \mathbf{7 d f c}$ and $\mathbf{7 d f m}$ was evaluated and the three compounds were found to possess an excellent stability profile with a $\mathrm{Cl}_{\text {int }}$ between 2.0 and $13.9 \mu \mathrm{L} / \mathrm{min} / \mathrm{mg}$ protein in mouse hepatic cells (Table 7). Their toxicity was measured against both normal cells (MRC-5) and cancer cells (HCT-116) and although 7dfm was found to have an $\mathrm{IC}_{50}$ in the 20-30 $\mu \mathrm{M}$ range, neither $7 \mathrm{dfa}$ nor $\mathbf{7 d f c}$ was found to be cytotoxic $\left(\mathrm{IC}_{50}>100 \mu \mathrm{M}\right)$. Finally, all three compounds were evaluated for the repotentiation of imipenem against the clinical strain of E. coli that expresses NDM-1 (amongst other genes of resistance).[56] In the absence of inhibitor, the MIC was above the resistance threshold at $16 \mu \mathrm{g} / \mathrm{mL}$. For $\mathbf{7 d f a}$, no effect was observed for concentrations up to $100 \mu \mathrm{M}$ (although at $200 \mu \mathrm{M}$, the MIC was eventually divided by two). In the presence of 50 $\mu \mathrm{M}$ (i.e. $30 \mu \mathrm{g} / \mathrm{mL}$ ) of $7 \mathrm{dfc}$, a notable effect was witnessed as the MIC was divided by 4 , bringing it down to the intermediate/resistant limit. The bacteria could be made susceptible again (with a MIC of $2 \mu \mathrm{g} / \mathrm{mL}$ ) by using $100 \mu \mathrm{M}(60 \mu \mathrm{g} / \mathrm{mL}$ ) of the compound. An effect was observed for $20 \mu \mathrm{M}$ (i.e. $10 \mu \mathrm{g} / \mathrm{mL}$ ) of $7 \mathrm{dfm}$, as the MIC was halved. Using $50 \mu \mathrm{M}$ (i.e. 25 $\mu \mathrm{g} / \mathrm{mL}$ ) of $7 \mathrm{dfm}$, it could be brought down to $4 \mu \mathrm{g} / \mathrm{mL}$, but no improvement could be made using a higher concentration of the inhibitor.

Table 7. Metabolic stability, cytotoxicity and imipenem repotentiation for $\mathbf{7 d f a ,} \mathbf{7 d f c}$ and 7dfm

\begin{tabular}{ccc|cc|cccc}
\multicolumn{3}{c|}{ Stability } & \multicolumn{2}{c|}{$\mathrm{IC}_{50}(\mu \mathrm{M})^{\mathrm{c}}$} & \multicolumn{4}{c}{$\mathrm{MIC}(\mu \mathrm{g} / \mathrm{mL})^{\mathrm{d}}$} \\
\hline & Non-NADPH $^{\mathrm{a}}$ & $\mathrm{CL}_{\text {int }} \mathrm{b}^{\mathrm{y}}$ & $\mathrm{MRC}-5$ & $\mathrm{HCT}-116$ & $0 \mu \mathrm{M}$ & $20 \mu \mathrm{M}$ & $50 \mu \mathrm{M}$ & $100 \mu \mathrm{M}$ \\
\hline $\mathbf{7 d f a}$ & $\mathbf{8 3 \%}$ & $\mathbf{2 . 0}$ & $>100$ & $>100$ & 16 & 16 & 16 & 16 \\
\hline $\mathbf{7 d f c}$ & $100 \%$ & $\mathbf{7 . 6}$ & $>100$ & $>100$ & 16 & 16 & 4 & 2 \\
\hline $\mathbf{7 d f m}$ & $96 \%$ & $\mathbf{1 3 . 9}$ & 19.9 & 32.3 & 16 & 8 & 4 & 4 \\
\hline
\end{tabular}


a Stability after $45 \mathrm{~min}$ in the presence of mouse hepatic microsome in the absence of NADPH; ${ }^{\mathrm{b}} \mathrm{CL}_{\text {int }}$ was determined using mouse hepatic microsomes and is given in $\mu \mathrm{L} / \mathrm{min} / \mathrm{mg}$ protein; ${ }^{c}$ inhibition of cell proliferation; ${ }^{d}$ Minimum inhibitory concentration for imipenem using E. coli GUE-NDM1[56] clinical strain. No antibiotic effect was observed when the bacteria were incubated with $\mathbf{7 d f a}, \mathbf{7 d f c}$ or $\mathbf{7 d f m}$ at $20 \mu \mathrm{M}, 50 \mu \mathrm{M}$ or $100 \mu \mathrm{M}$.

\subsection{Molecular modeling}

Compound $\mathbf{7 d f m}$ was selected for a more in-depth study of the interaction with NDM-1, KPC-2 and OXA-48. The docking of these enzymes with the two enantiomers of $\mathbf{7 d f m}$ was performed using GOLD[57] and the results for NDM-1 are presented in Figure 3 and those for KPC-2 and OXA-48 in Figure S1 (see Supplementary Information).

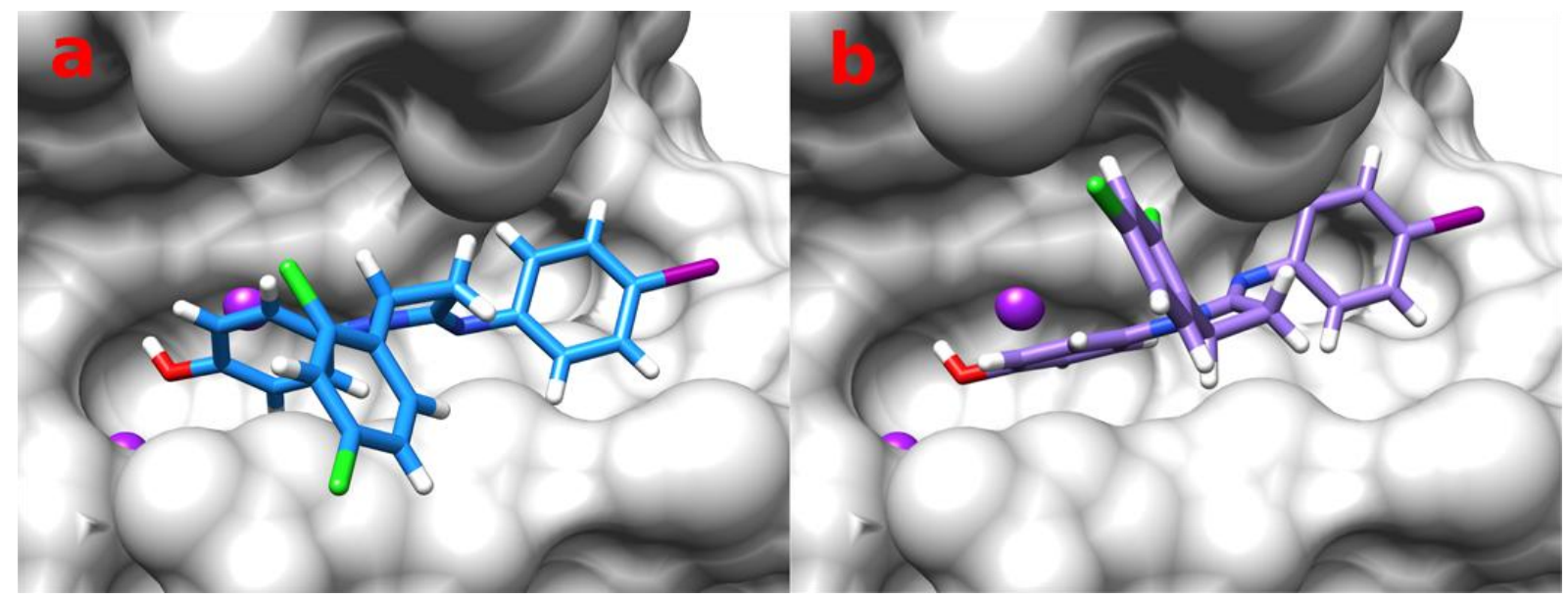

Figure 3: Docking conformations of the $R(\mathbf{a})$ and $S(\mathbf{b})$ enantiomers of compound $\mathbf{7 d f m}$, in the active site of NDM-1 (class $B$ ) represented as gray surface; the zinc ions are colored in purple.

Both enantiomers of $\mathbf{7 d f m}$ appear to interact with NDM-1 in a similar manner as 7aaa (see

Figure 2). The phenol moiety would be coordinated with the two zinc ions and the 4-iodophenyl substituent positioned in the same subpocket in both cases, possibly establishing a stabilizing halogen bond with the side-chain of Asp212. This would position the 2,4-dichlorophenyl substituent in a hydrophobic environment bordered by residues Val73, Ile35, Met67 and Phe70 for the $S$ enantiomer (Figure $3 b$ ) and in the vicinity of Asn220 for the $R$ enantiomer (Figure 3a). 
A comparison between this modeling and the crystallographic structures of NDM-1 in complexes with various ligands published recently[38,39] would suggest that our compounds bind more deeply in the NDM-1 active site cavity and explore different subpockets (Figure S2, see Supplementary Information). Particularly interesting is the lack of inhibition observed for VIM-52, in contrast with VIM-1, as VIM-52 is a His224Arg variant of VIM-1[55] and this mutation occurs in the L3 loop, which is known to play a role in substrate recognition and specificity.[58,59] Although its carbapenemase activity remains the same, the hydrolysis of ceftazidime and cefepime is slower. Superposition of the two VIM variants on the docking conformations of the $\mathbf{7 d f m}$ enantiomers shows that the loss of activity for VIM-52 could indeed be due to the impossibility of the compound to access the active site, as opposed to VIM-1. This difference is mainly due to the formation of a salt bridge between Arg224 and Glu225, which blocks a significant part of the binding pocket in VIM-52. This salt bridge cannot be formed between His224 and Glu225 in VIM-1. Under these conditions, only minor steric hindrance with the 4-iodo substituent of $\mathrm{Ar}^{1}$ is observed in $\mathrm{VIM}-1$, whereas important clashes are present between $\mathrm{Ar}^{1}$ and the residues $\mathrm{Arg} 224$ and Glu225 in VIM-52 (Figure S3, see Supplementary Information). It is worth nothing that this different behavior of 7dfm towards VIM-1 and VIM-52 provides experimental support for the binding mode proposed here, confirming that 7dfm interacts with the L3 loop of NDM-1 and VIM-1, which is not the case with the metallo- $\beta$-lactamase inhibitors reported recently by Renslo and Chen[38,39] (Figure S2).

\section{CONCLUSIONS}

The evaluation of azetidinimines, imino-analogues of $\beta$-lactams, as $\beta$-lactamase inhibitors led to the development of a new family of non-covalent carbapenemase inhibitors.[38,39] Structural optimization led to the identification of phenol $\mathbf{7 d f m}$ as the lead compound, which 
can strongly inhibit class B MBL NDM-1, class A SBL KPC-2 and class D SBL OXA-48 with Ki's of $0.07,0.28$ and $0.07 \mu \mathrm{M}$, respectively, which compared quite favorably with the most recently developed MBL-specific and poly-carbapenemase inhibitors (see Figure 1). This molecule can also inhibit other MBLs (NDM-4, NDM-7, NDM-9 and VIM-1), as well as a class C cephalosporinase (CMY-2). Molecular modeling with NDM-1 showed that this compound does not mimic a $\beta$-lactam within the enzyme active sites and that both enantiomers can interact with the enzymes. While this gives hints towards the mode of action of these derivatives against NDM- 1 as the prototypical MBL, there are chances that they act in a very different fashion against SBLs. Studies are underway to ascertain the mode of actions of this family of compounds against specific SBLs. The lead compound $\mathbf{7 f d m}$ and two submicromolar inhibitors of NDM-1 7dfa \& 7dfc exhibited excellent metabolic stability and moderate to very low cytotoxicity. Significant repotentiation of imipenem against an NDM-1 expressing resistant $E$. coli strain was achieved with both $\mathbf{7} \mathbf{d f m}$ and $\mathbf{7} \mathbf{d f c}$. Further refinement of the structure of these molecules will be pursued to improve the efficiency and the druglike properties of these $\beta$-lactamase pan inhibitors, before initiating in vivo studies.

\section{MATERIALS AND METHODS}

\subsection{General Procedure for Azetidinimine Synthesis.}

The imine (1.0 equiv.), the ynamide ( 2.0 equiv.) and the additive - silica gel (1.0 equiv.) or $\mathrm{ZnOTf}_{2}(10$ mol\%) - were successively added in a microwave sealable tube and placed under argon before the addition of $t$-BuOLi - solid or $2.2 \mathrm{M}$ in solution in THF - (2.0 equiv.) followed by extra dry DMF (0.3M). The sealed tube was placed in a microwave apparatus for $1 \mathrm{~h}$ at $100{ }^{\circ} \mathrm{C}$. The crude material was purified by flash chromatography on silica gel or by preparative TLC. See Supporting Information for detailed synthetic procedures and characterizations of the compounds. 


\subsection{Cloning of the NDM-1, OXA-48 and KPC-2 Genes.}

The sequences without the peptide signal (predicted by SignallP 4.1 Server) of bla $a_{\mathrm{NDM}-1}$, bla $a_{\mathrm{OXA}-48}$ and $b / a_{\mathrm{KPC}-2}$ genes, encoding for the mature proteins: NDM-1( from amino 29 to 293), OXA-48 (from amino 23 to 261), KPC-2 (from amino 30 to 293) and deleted of the stop codon, were amplified by PCR using primers including Ndel and Xhol restriction sites. Then, PCR product was cloned into pET41b vector (Invitrogen ${ }^{\circledR}$, Life Technologies, Cergy-Pontoise, France), using Ndel and Xhol restriction enzymes, to obtain a C-Term His8-tag. The accuracy of the recombinant plasmid was verified by sequencing, using a T7 promoter and T7 terminator with an ABI Prism 3100 automated sequencer (Applied Biosystems, Thermo Fisher Scientific, Les Ulis, France). The nucleotide sequences were analyzed by using software available at the National Center for Biotechnology Information website (http://www.ncbi.nlm.nih.gov).

\subsection{Protein Expression and Purification for NDM-1, OXA-48 and KPC-2.}

The recombinant plasmids harboring $\beta$-lactamase genes were transformed into $E$. coli BL21 (DE3), and an overnight culture was used to inoculate $2 \mathrm{~L}$ of Luria Bertani medium broth containing $50 \mu \mathrm{g} / \mathrm{mL}$ of kanamycin. Bacteria were cultured at $37^{\circ} \mathrm{C}$, until an OD of 0.6 at 600 $\mathrm{nm}$ was reached. The expression of the $\beta$-lactamase genes was carried out at $37^{\circ} \mathrm{C}$ for $3 \mathrm{~h}$, with $1 \mathrm{mM}$ of IPTG as an inducer. Cells were pelleted by centrifugation, at $6000 \mathrm{~g}$ for $15 \mathrm{~min}$, then resuspended with $25 \mathrm{mM}$ of phosphate sodium $\mathrm{pH} 7.4,300 \mathrm{mM}$ of $\mathrm{K}_{2} \mathrm{SO}_{4}$ (for OXA-48) or $\mathrm{NaCl}$ (for NDM-1 and $\mathrm{KPC}-2$ ), and $10 \mathrm{mM}$ of imidazole. Bacterial cells were disrupted by sonication, and the bacteria debris was removed by 2 centrifugations: first at 10,000 g for 1 $\mathrm{h}$ at $4^{\circ} \mathrm{C}$, and then the supernatants obtained were centrifuged at $96,000 \mathrm{~g}$ for $1 \mathrm{~h}$ at $4{ }^{\circ} \mathrm{C}$. The soluble fraction was filtered and then passed through a HisTrap ${ }^{\mathrm{TM}} \mathrm{HP}$ column (GE Healthcare ${ }^{\circledR}$, Velizy-Villacoublay, France). The recombinant proteins were eluted, using 
elution buffer ( $25 \mathrm{mM}$ of phosphate sodium pH 7.4, $300 \mathrm{mM}$ of $\mathrm{K}_{2} \mathrm{SO}_{4}$ or $\mathrm{NaCl}$, and $500 \mathrm{mM}$ of imidazole). The eluted proteins were concentrated by using Vivaspin 20 (10000 MWCOPES Sartorius $^{\circledast}$, Aubagne, France), dialyzed against $0.1 \mathrm{M}$ of HEPES (pH 7.5) buffer and $150 \mathrm{mM}$ $\mathrm{K}_{2} \mathrm{SO}_{4}$ or $\mathrm{NaCl}$ and then loaded onto a HiLoad 16/600 Superdex $75 \mathrm{pg}$ (GE Healthcare). The protein purity, estimated by SDS-PAGE (see Figures S4-S6 in the supplementary information), was more than $99 \%$, and the pooled fractions were dialyzed against $100 \mathrm{mM}$ sodium phosphate buffer $\mathrm{pH} 7$ (and $50 \mu \mathrm{M} \mathrm{ZnSO}_{4}$ for NDM-1) and concentrated, using Vivaspin columns. Protein concentration was determined by Bradford Protein assay (BioRad, Marnes-La-Coquette, France).

\subsection{In vitro $\beta$-lactamase inhibition assay.}

Spectrophotometric assays were performed using ULTROSPEC 2000 UV spectrophotometer and the SWIFT II software (GE Healthcare, Velizy-Villacoublay, France). Assay conditions were as follows: $100 \mathrm{mM}$ phosphate buffer, $\mathrm{pH} 7$ (supplemented with $50 \mu \mathrm{M} \mathrm{ZnSO}{ }_{4}$ when testing NDM-1, and with $50 \mathrm{mM} \mathrm{NaHCO}{ }_{3}[60,61]$ when testing OXA-48), $100 \mu \mathrm{M}$ imipenem (Sigma-aldrich, Saint-Quentin Fallavier, France). The reaction was monitored at $297 \mathrm{~nm}$, time course 600 seconds at $25{ }^{\circ} \mathrm{C}$ with 3 min of incubation (compound/carbapenemase). Enzyme concentration were : $1 \mathrm{nM}$ for NDM-1, $1.7 \mathrm{nM}$ for KPC-2 and $5.8 \mathrm{nM}$ for OXA-48. Initial steady-state velocities from imipenem hydrolysis were measured at a wavelength of $297 \mathrm{~nm}$. $\mathrm{IC}_{50}$ values for each inhibitor compound were assayed at seven different concentrations, and performed in triplicate. The $K_{i}$ of each inhibitor was calculated according to the Cheng-Prusoff equation: $K_{i}=\mathrm{IC} 50 /(1+[\mathrm{S}] / \mathrm{Km})$, where $[\mathrm{S}]$ is the imipenem concentration and $\mathrm{Km}$ is the Michaelis constant of the enzymes.[62] Percentage of inhibition was determined when the $\mathrm{IC}_{50}$ of the compound was lower than $10 \mu \mathrm{M}$.

\subsection{Minimal Inhibition concentrations.}


MIC values were determined by broth microdilution, in triplicate, in cation-adjusted Mueller Hinton broth according to the Clinical Laboratory Standards Institute (CLSI, https://clsi.org/) guidelines. The enterobacterial clinical strain E. coli NDM-1 GUE expressing the carbapenemase NDM-1 was used.[56] Experiments were performed in microtiter plates containing the medium with imipenem and inhibitors (dissolved in DMSO). Three inhibitor concentrations were tested: 50, 100 and $200 \mu \mathrm{M}$. Plates were incubated overnight at $37^{\circ} \mathrm{C}$ for 18-24 h. In all MIC assays, a negative control (bacteria incubated with different concentrations of compound) was performed. No antibiotic effect was observed, for all the compounds, even with the highest concentration tested (200 $\mu \mathrm{M})$.

\subsection{Incubations in hepatic microsomes.}

Compounds $(5 \mu \mathrm{M})$ were incubated in $0.5 \mathrm{mg} / \mathrm{mL}$ of pooled male mouse liver microsomes (from Biopredic, France), in $0.1 \mathrm{M}$ phosphate buffer at $\mathrm{pH} 7.4$ at $37{ }^{\circ} \mathrm{C}$. After prewarming the mixture for $5 \mathrm{~min}$, reactions were initiated by the addition of NADPH (1 mM). Incubations $\left(400 \mu \mathrm{L}\right.$ ) were performed at $37^{\circ} \mathrm{C}$ for $0,5,15,30$ and $45 \mathrm{~min}$ in duplicate and the reaction immediately terminated by adding $200 \mu \mathrm{L}$ of cold acetonitrile. Samples (including the control to evaluate non NADPH-dependent stability) were centrifuged and the supernatant fractions analyzed by UPLC-MS/MS with multiple reaction monitoring (MRM). Diphenhydramine was used as positive control in the mouse liver microsomes tests. The MRM area response of the analyte was set to $100 \%$ with the T0 incubation, the relative decrease in MRM area ratio intensity over time against that of the control (percent parent decrease) was used to determine the half-life $(\mathrm{t} 1 / 2)$ of compounds in the incubation. Half-life values were calculated from the relationship: 
$\mathrm{T} 1 / 2(\mathrm{~min})=0.693 / \mathrm{k}$, where $\mathrm{k}$ is the slope of the Ln concentration vs time curve. The intrinsic clearance (CLint) was calculated as: CLint $=(0.693 \times$ incubation volume $(\mu \mathrm{L})) /(\mathrm{t}(\mathrm{min}) \times \mathrm{mg}$ of microsomal protein).

\subsection{Cell culture and proliferation assay.}

Assays were carried out at the Institut de Chimie des Substances Naturelles by the CIBI screening platform. Cell lines were obtained from the American Type Culture Collection (Rockville, USA) and were cultured according to the supplier's instructions. Briefly, human MRC-5 cells were grown in DMEM supplemented with $10 \%$ fetal calf serum (FCS) and $1 \%$ glutamine and HCT116 colorectal carcinoma cells were grown in RPMI 1640 containing 10\% FCS and $1 \%$ glutamine. All cell lines were maintained at $37{ }^{\circ} \mathrm{C}$ in a humidified atmosphere containing $5 \% \mathrm{CO}_{2}$. Cell growth inhibition was determined by an MTS assay according to the manufacturer's instructions (Promega, Madison, WI, USA). Briefly, the cells were seeded in 96-well plates $(2.5 \times 103$ cells/well) containing $200 \mu \mathrm{L}$ of growth medium. After $24 \mathrm{~h}$ of culture, the cells were treated with the test compounds at different final concentrations. After $72 \mathrm{~h}$ of incubation, $40 \mu \mathrm{L}$ of resazurin was added for $2 \mathrm{~h}$ before recording absorbance at $490 \mathrm{~nm}$ with a spectrophotometric plate reader. The $\mathrm{IC}_{50}$ value corresponded to the concentration of compound inducing a decrease of $50 \%$ in absorbance of drug-treated cells compared with untreated cells. Experiments were performed in triplicate. Paclitaxel was used as the reference compound.

4.8 PCR, Cloning, Expression, and DNA Sequencing for NDM-4, NDM-7, NDM-9, VIM-1, VIM-52, CTX-M-15 and CMY-2.

Whole-cell DNA of the enterobacterales expressing $\beta$-lactamases NDM-4, NDM-7, NDM-9, VIM-1, VIM-52, CTX-M-15 and CMY-2 was extracted, using the QIAamp DNA mini kit (Qiagen, Courtaboeuf, France) and used as a template to amplify all the different genes. The 
sequences without the peptide signal (predicted by SignallP 4.1 Server, http://www.cbs.dtu.dk/services/SignalP-4.1/) encoding for the mature protein, were obtained by PCR amplification, using the forward primers, which included an Ndel restriction site, and the reverse primer which included an Xhol restriction site and a deletion of the stop codon of the gene to allow the expression of an C_Term His tag. Then, PCR product was cloned into pET41b vector (Invitrogen ${ }^{\circledR}$, Life Technologies, Cergy-Pontoise, France), using Ndel and Xhol restriction enzymes, to obtain a C-Term Hisz-tag. The accuracy of the recombinant plasmid was verified by sequencing, using a T7 promoter and $\mathrm{T} 7$ terminator with an ABI Prism 3100 automated sequencer (Applied Biosystems, Thermo Fisher Scientific, Les Ulis, France). The nucleotide sequences were analyzed by using software available at the National Center for Biotechnology Information website (http://www.ncbi.nlm.nih.gov).

\subsection{Protein purification for NDM-4, NDM-7, NDM-9, VIM-1, VIM-52, CTX-M-15 and CMY-2.}

An overnight culture of $E$. coli BL21 DE3 harboring recombinant $\mathrm{pET} 41 \mathrm{~b}$ plasmids was used to inoculate $2 \mathrm{~L}$ of LB medium broth containing $50 \mathrm{mg} / \mathrm{L}$ kanamycin. Bacteria were cultured at $37^{\circ} \mathrm{C}$ until an OD of 0.6 at $600 \mathrm{~nm}$ was reached. The expression of the $\beta$-lactamase genes was carried out overnight at $22{ }^{\circ} \mathrm{C}$ with $0.2 \mathrm{mM}$ IPTG as inducer. Cultures were centrifuged at $6000 \mathrm{~g}$ for $15 \mathrm{~min}$ and then the pellets were resuspended with the binding buffer $(10 \mathrm{mM}$ imidazole, $25 \mathrm{mM}$ sodium phosphate $\mathrm{pH} 7.4$ and $300 \mathrm{mM} \mathrm{NaCl}$ ). Bacterial cells were disrupted by sonication and the bacterial pellet was removed by two consecutive centrifugation steps at $10000 \mathrm{~g}$ for $1 \mathrm{~h}$ at $4{ }^{\circ} \mathrm{C}$; the supernatant was then centrifuged at $96000 \mathrm{~g}$ for $1 \mathrm{~h}$ at $4^{\circ} \mathrm{C}$. The soluble fractions were filtered and then passed through a HisTrapTM HP column (GE Healthcare) and proteins were eluted with the elution buffer (500 $\mathrm{mM}$ imidazole, $25 \mathrm{mM}$ sodium phosphate $\mathrm{pH} 7.4$ and $300 \mathrm{mM} \mathrm{NaCl}$ ). Finally, a gel filtration step was performed with $100 \mathrm{mM}$ sodium phosphate buffer $\mathrm{pH} 7$ and $150 \mathrm{mM} \mathrm{NaCl}$ with a 
Superdex 75 column (GE Healthcare). The protein purity was estimated by SDS-PAGE. The pooled fractions were dialyzed against $10 \mathrm{mM}$ Tris- $\mathrm{HCl} \mathrm{pH}$ 7.6, $50 \mu \mathrm{M}$ of $\mathrm{ZnSO}_{4}$ was added for NDM and VIM, then concentrated using Vivaspin columns (Sartorius, Aubagne, France). The concentrations were determined by measuring the $O D$ at $280 \mathrm{~nm}$ and with the extinction coefficients obtained from the ProtParam tool (Swiss Institute of Bioinformatics online resource portal).[63]

\subsection{Molecular modeling.}

The three-dimensional structure of compound 7aaa[52] was retrieved from the Cambridge Structural Database[64] (CSD refcode KEMJEU) and that of compound 7dfm was built starting from 7aaa by manual editing using UCSF Chimera package.[65] The structures of enantiomers were generated using an in-house script. Molecular docking was performed using the GOLD suite[57] (CCDC) and the GoldScore scoring function, with the structures $4 \mathrm{HL} 2,[66]$ 2OV5[67] and 4S2P[68] as receptors for NDM-1, KPC-2 and OXA-48, respectively. The binding sites were defined as $15 \AA$ radius spheres centered on the $\mathrm{Zn} 1$ ion for NDM-1 and on the OG atom of Ser70 for KPC-2 and OXA-48. In agreement with our previous studies[69-75] showing that an enhanced conformational search is beneficial, especially for large molecules, a search efficiency of $200 \%$ was used to better explore the ligand conformational space. All other parameters were used with the default values. The VIM-52 structure was generated from the crystallographic structure of VIM-1 (PDB code $5 \mathrm{~N} 5 \mathrm{I}$ )[76] by the in silico mutation His224Arg using UCSF Chimera,[65] followed by energy minimization of Arg224 and Glu225 to optimize the ionic interaction between these two residues. Images were generated using UCSF Chimera.[65]

\section{Supporting Information}


The Supporting Information contains detailed synthetic procedures and characterizations of the compounds, the data obtained from the docking of KPC-2 and OXA-48 with 7dfm, interaction of 7dfm with VIM-1 and VIM-52, and the copies of the NMR spectra.

\section{Author Information}

\section{Corresponding authors:}

*E-mail: kevin.cariou@cnrs.fr

*E-mail:bogdan.iorga@cnrs.fr.

*E-mail:thierry.naas@aphp.fr.

\section{ORCID:}

Mohamed Benchekroun: 0000-0002-0063-0139

Alain Pruvost: 0000-0002-7781-7735

Thierry Naas: 0000-0001-9937-9572

Bogdan I. lorga: 0000-0003-0392-1350

Robert H. Dodd: 0000-0001-6477-3609

Kevin Cariou: 0000-0002-5854-9632

\section{Author Contributions}

This study was conceived by K. Cariou, B. I. lorga, T. Naas and R. H. Dodd. Synthesis and characterization of the compounds were performed by E. Romero, M. Benchekroun, S. Ventre, A. C. A. D'Hollander, K. Vijayakumar and C. Minard. Purification of the proteins, inhibition assays and MIC assays were performed by S. Oueslati with C. Exilie, L. Tlili and A. Zavala. Metabolic studies were performed by L. A. Nguyen under the supervision of A. Pruvost. Structural analysis and molecular modeling studies were performed by A. Zavala, E. Elisée, E. Selwa, P. Retailleau and B. I. Iorga. K. Cariou and B. I. Iorga drafted the manuscript which was amended and commented on by all authors.

\# E. R. \& S. O contributed equally; $\diamond$ M. B. \& A. C. A. D. contributed equally 
Conflict of Interest Disclosure: The authors declare no competing financial interest

\section{List of Abbreviations}

CTX-M-15: Cefotaximase-Munich 15

CMY-2: Cephamycinase-2

DMSO: dimethyl sulfoxide

GNB: Gram-negative Bacilli

HCT-116: Human Colorectal Carcinoma cells

KPC: Klebsiella Pneumoniae Carbapenemase

MBL: Metallo- $\beta$-lactamase

MIC: Minimum Inhibitory Concentrations

MRC-5: Medical Research Council cell strain 5

ND: Not Determined

NDM: New Delhi metallo- $\beta$-lactamase

NE: no effect

OXA: Oxacillinase

SAR: Structure Activity Relationship

SBL: Serine- $\beta$-lactamases

VIM: Verona Integron metallo- $\beta$-lactamase

\section{Acknowledgments}

This work was supported by the Laboratory of Excellence in Research on Medication and Innovative Therapeutics (LERMIT, grant ANR-10-LABX-33 under the program Investissements d'Avenir ANR-11-IDEX-0003-01), the FCS Campus Paris-Saclay pre-maturation program (project Inhibase), the SATT Paris-Saclay (project CARBAMAT), the JPIAMR transnational 
project DesInMBL (grant ANR-14-JAMR-0002) and the Région lle-de-France (DIM Malinf). The

authors also thank CNRS, AP-HP, Université Paris-Saclay, and ICSN, for financial support.

\section{References}

[1] J. O'Neill, Tackling drug-resistant infections globally: final report and recommendations. https://amr-review.org/sites/default/files/160525_Final\%20paper_with\%20cover.pdf, 2016.

[2] P. Nordmann, T. Naas, N. Fortineau, L. Poirel, Superbugs in the coming new decade; multidrug resistance and prospects for treatment of Staphylococcus aureus, Enterococcus spp. and Pseudomonas aeruginosa in 2010, Curr. Opin. Microbiol. 10 (2007) 436-440.

[3] P. Nordmann, T. Naas, L. Poirel, Global spread of carbapenemase-producing enterobacteriaceae, Emerg. Infect. Dis. 17 (2011) 1791-1798.

[4] R.J. Worthington, C. Melander, Overcoming resistance to $\beta$-lactam antibiotics, J. Org. Chem. 78 (2013) 4207-4213.

[5] M.F. Chellat, L. Raguž, R. Riedl, Targeting Antibiotic Resistance, Angew. Chem. Int. Ed. 55 (2016) 6600-6626.

[6] C. González-Bello, D. Rodríguez, M. Pernas, Á. Rodríguez, E. Colchón, $\beta$-Lactamase Inhibitors To Restore the Efficacy of Antibiotics against Superbugs, J. Med. Chem. 63 (2020) 1859-1881.

[7] C.L. Tooke, P. Hinchliffe, E.C. Bragginton, C.K. Colenso, V.H.A. Hirvonen, Y. Takebayashi, J. Spencer, $\beta-$ Lactamases and $\beta$-Lactamase Inhibitors in the 21st Century, J. Mol. Biol. 431 (2019) 3472-3500.

[8] J.C. Vázquez-Ucha, J. Arca-Suárez, G. Bou, A. Beceiro, New Carbapenemase Inhibitors: Clearing the Way for the $\beta$-Lactams, Int. J. Mol. Sci. 21 (2020) 9308.

[9] D.E. Ehmann, H. Jahić, P.L. Ross, R.-F. Gu, J. Hu, G. Kern, G.K. Walkup, S.L. Fisher, Avibactam is a covalent, reversible, non- $\beta$-lactam $\beta$-lactamase inhibitor, Proc. Natl. Acad. Sci. 109 (2012) 1166311668.

[10] D.Y. Wang, M.I. Abboud, M.S. Markoulides, J. Brem, C.J. Schofield, The road to avibactam: the first clinically useful non- $\beta$-lactam working somewhat like a $\beta$-lactam, Future Med. Chem. 8 (2016) 10631084.

[11] S.J. Hecker, K.R. Reddy, M. Totrov, G.C. Hirst, O. Lomovskaya, D.C. Griffith, P. King, R. Tsivkovski, D. Sun, M. Sabet, Z. Tarazi, M.C. Clifton, K. Atkins, A. Raymond, K.T. Potts, J. Abendroth, S.H. Boyer, J.S. Loutit, E.E. Morgan, S. Durso, M.N. Dudley, Discovery of a cyclic boronic acid $\beta$-lactamase inhibitor (RPX7009) with utility vs class A Serine carbapenemases, J. Med. Chem. 58 (2015) 3682-3692.

[12] E.B. Hirsch, K.R. Ledesma, K.-T. Chang, M.S. Schwartz, M.R. Motyl, V.H. Tam, In vitro activity of MK7655 , a novel $\beta$-lactamase inhibitor, in combination with imipenem against carbapenem-resistant Gram-egativne bacteria, Antimicrob. Agents Chemother. 56 (2012) 3753-3757.

[13] A. Morinaka, Y. Tsutsumi, M. Yamada, K. Suzuki, T. Watanabe, T. Abe, T. Furuuchi, S. Inamura, Y. Sakamaki, N. Mitsuhashi, T. Ida, D.M. Livermore, OP0595, a new diazabicyclooctane: mode of action as a serine $\beta$-lactamase inhibitor, antibiotic and $\beta$-lactam 'enhancer,' J. Antimicrob. Chemother. 70 (2015) 2779-2786.

[14] D.M. Livermore, S. Mushtaq, M. Warner, A. Vickers, N. Woodford, In vitro activity of cefepime/zidebactam (WCK 5222) against Gram-negative bacteria, J. Antimicrob. Chemother. 72 (2017) 1373-1385.

[15] T.F. Durand-Réville, S. Guler, J. Comita-Prevoir, B. Chen, N. Bifulco, H. Huynh, S. Lahiri, A.B. Shapiro, S.M. McLeod, N.M. Carter, S.H. Moussa, C. Velez-Vega, N.B. Olivier, R. McLaughlin, N. Gao, J. Thresher, T. Palmer, B. Andrews, R.A. Giacobbe, J.V. Newman, D.E. Ehmann, B. de Jonge, J. O’Donnell, J.P. Mueller, R.A. Tommasi, A.A. Miller, ETX2514 is a broad-spectrum $\beta$-lactamase inhibitor for the treatment of drug-resistant Gram-negative bacteria including Acinetobacter baumannii, Nat. Microbiol. 2 (2017) 17104.

[16] Z. Edoo, L. Iannazzo, F. Compain, I. Li de la Sierra Gallay, H. van Tilbeurgh, M. Fonvielle, F. Bouchet, E. Le Run, J.-L. Mainardi, M. Arthur, M. Ethève-Quelquejeu, J.-E. Hugonnet, Synthesis of Avibactam Derivatives and Activity on $\beta$-Lactamases and Peptidoglycan Biosynthesis Enzymes of Mycobacteria, Chem. - Eur. J. 24 (2018) 8081-8086.

[17] L. Peilleron, K. Cariou, Synthetic approaches towards avibactam and other diazabicyclooctane $\beta$ lactamase inhibitors, Org. Biomol. Chem. 18 (2020) 830-844. 
[18] D.T. Davies, S. Leiris, M. Zalacain, N. Sprynski, J. Castandet, J. Bousquet, C. Lozano, A. Llanos, L. Alibaud, S. Vasa, R. Pattipati, R. Valige, B. Kummari, S. Pothukanuri, C. De Piano, I. Morrissey, K. Holden, P. Warn, F. Marcoccia, M. Benvenuti, C. Pozzi, G. Tassone, S. Mangani, J.-D. Docquier, D. Pallin, R. Elliot, M. Lemonnier, M. Everett, Discovery of ANT3310, a Novel Broad-Spectrum Serine $\beta$ Lactamase Inhibitor of the Diazabicyclooctane Class, Which Strongly Potentiates Meropenem Activity against Carbapenem-Resistant Enterobacterales and Acinetobacter baumannii, J. Med. Chem. 63 (2020) 15802-15820.

[19] T.F. Durand-Réville, J. Comita-Prevoir, J. Zhang, X. Wu, T.L. May-Dracka, J.A.C. Romero, F. Wu, A. Chen, A.B. Shapiro, N.M. Carter, S.M. McLeod, R.A. Giacobbe, J.C. Verheijen, S.D. Lahiri, M.D. Sacco, Y. Chen, J.P. O’Donnell, A.A. Miller, J.P. Mueller, R.A. Tommasi, Discovery of an Orally Available Diazabicyclooctane Inhibitor (ETX0282) of Class A, C, and D Serine $\beta$-Lactamases, J. Med. Chem. 63 (2020) 12511-12525.

[20] F. Bouchet, H. Atze, M. Fonvielle, Z. Edoo, M. Arthur, M. Ethève-Quelquejeu, L. Iannazzo, Diazabicyclooctane Functionalization for Inhibition of $\beta$-Lactamases from Enterobacteria, J. Med. Chem. 63 (2020) 5257-5273.

[21] K. Durka, A.E. Laudy, Ł. Charzewski, M. Urban, K. Stępień, S. Tyski, K.A. Krzyśko, S. Luliński, Antimicrobial and KPC/AmpC inhibitory activity of functionalized benzosiloxaboroles, Eur. J. Med. Chem. 171 (2019) 11-24.

[22] P. Linciano, L. Cendron, E. Gianquinto, F. Spyrakis, D. Tondi, Ten years with New Delhi metallo- $\beta$ lactamase-1 (NDM-1): from structural insights to inhibitor design, ACS Infect. Dis. 5 (2019) 9-34.

[23] C. Chen, K.-W. Yang, Structure-based design of covalent inhibitors targeting metallo- $\beta$-lactamases, Eur. J. Med. Chem. 203 (2020) 112573.

[24] S.B. Falconer, S.A. Reid-Yu, A.M. King, S.S. Gehrke, W. Wang, J.F. Britten, B.K. Coombes, G.D. Wright, E.D. Brown, Zinc Chelation by a Small-Molecule Adjuvant Potentiates Meropenem Activity in Vivo against NDM-1-Producing Klebsiella pneumoniae, ACS Infect. Dis. 1 (2015) 533-543.

[25] K.H.M.E. Tehrani, N.I. Martin, Thiol-containing metallo- $\beta$-lactamase inhibitors resensitize resistant Gram-negative bacteria to meropenem, ACS Infect. Dis. 3 (2017) 711-717.

[26] S. Liu, L. Jing, Z.-J. Yu, C. Wu, Y. Zheng, E. Zhang, Q. Chen, Y. Yu, L. Guo, Y. Wu, G.-B. Li, ((S)-3Mercapto-2-methylpropanamido)acetic acid derivatives as metallo- $\beta$-lactamase inhibitors: Synthesis, kinetic and crystallographic studies, Eur. J. Med. Chem. 145 (2018) 649-660.

[27] F.-M. Klingler, T.A. Wichelhaus, D. Frank, J. Cuesta-Bernal, J. El-Delik, H.F. Müller, H. Sjuts, S. Göttig, A. Koenigs, K.M. Pos, D. Pogoryelov, E. Proschak, Approved drugs containing thiols as inhibitors of metallo- $\beta$-lactamases: strategy to combat multidrug-resistant bacteria, J. Med. Chem. 58 (2015) 3626-3630.

[28] A.M. King, S.A. Reid-Yu, W. Wang, D.T. King, G. De Pascale, N.C. Strynadka, T.R. Walsh, B.K. Coombes, G.D. Wright, Aspergillomarasmine A overcomes metallo- $\beta$-lactamase antibiotic resistance, Nature. 510 (2014) 503-506.

[29] A.Y. Chen, C.A. Thomas, P.W. Thomas, K. Yang, Z. Cheng, W. Fast, M.W. Crowder, S.M. Cohen, Iminodiacetic Acid as a Novel Metal-Binding Pharmacophore for New Delhi Metallo- $\beta$-lactamase Inhibitor Development, ChemMedChem. 15 (2020) 1272-1282.

[30] K.H.M.E. Tehrani, N.C. Brüchle, N. Wade, V. Mashayekhi, D. Pesce, M.J. van Haren, N.I. Martin, Small Molecule Carboxylates Inhibit Metallo- $\beta$-lactamases and Resensitize Carbapenem-Resistant Bacteria to Meropenem, ACS Infect. Dis. 6 (2020) 1366-1371.

[31] Y. Xiang, C. Chen, W.-M. Wang, L.-W. Xu, K.-W. Yang, P. Oelschlaeger, Y. He, Rhodanine as a potent scaffold for the development of broad-spectrum metallo- $\beta$-lactamase inhibitors, ACS Med. Chem. Lett. 9 (2018) 359-364.

[32] J. Brem, S.S. van Berkel, W. Aik, A.M. Rydzik, M.B. Avison, I. Pettinati, K.-D. Umland, A. Kawamura, J. Spencer, T.D.W. Claridge, M.A. McDonough, C.J. Schofield, Rhodanine hydrolysis leads to potent thioenolate mediated metallo- $\beta$-lactamase inhibition, Nat. Chem. 6 (2014) 1084-1090.

[33] R.P. McGeary, D.T.C. Tan, C. Selleck, M. Monteiro Pedroso, H.E. Sidjabat, G. Schenk, Structure-activity relationship study and optimisation of 2-aminopyrrole-1-benzyl-4,5-diphenyl-1H-pyrrole-3carbonitrile as a broad spectrum metallo- $\beta$-lactamase inhibitor, Eur. J. Med. Chem. 137 (2017) 351364.

[34] L. Gavara, L. Sevaille, F. De Luca, P. Mercuri, C. Bebrone, G. Feller, A. Legru, G. Cerboni, S. Tanfoni, D. Baud, G. Cutolo, B. Bestgen, G. Chelini, F. Verdirosa, F. Sannio, C. Pozzi, M. Benvenuti, K. Kwapien, M. Fischer, K. Becker, J.-M. Frère, S. Mangani, N. Gresh, D. Berthomieu, M. Galleni, J.-D. Docquier, J.-F. Hernandez, 4-Amino-1,2,4-triazole-3-thione-derived Schiff bases as metallo- $\beta$-lactamase inhibitors, Eur. J. Med. Chem. 208 (2020) 112720. 
[35] D.T. Davies, S. Leiris, N. Sprynski, J. Castandet, C. Lozano, J. Bousquet, M. Zalacain, S. Vasa, P.K. Dasari, R. Pattipati, N. Vempala, S. Gujjewar, S. Godi, R. Jallala, R.R. Sathyap, N.A. Darshanoju, V.R. Ravu, R.R. Juventhala, N. Pottabathini, S. Sharma, S. Pothukanuri, K. Holden, P. Warn, F. Marcoccia, M. Benvenuti, C. Pozzi, S. Mangani, J.-D. Docquier, M. Lemonnier, M. Everett, ANT2681: SAR Studies Leading to the Identification of a Metallo- $\beta$-lactamase Inhibitor with Potential for Clinical Use in Combination with Meropenem for the Treatment of Infections Caused by NDM-Producing Enterobacteriaceae, ACS Infect. Dis. 6 (2020) 2419-2430.

[36] S. Leiris, A. Coelho, J. Castandet, M. Bayet, C. Lozano, J. Bougnon, J. Bousquet, M. Everett, M. Lemonnier, N. Sprynski, M. Zalacain, T.D. Pallin, M.C. Cramp, N. Jennings, G. Raphy, M.W. Jones, R. Pattipati, B. Shankar, R. Sivasubrahmanyam, A.K. Soodhagani, R.R. Juventhala, N. Pottabathini, S. Pothukanuri, M. Benvenuti, C. Pozzi, S. Mangani, F. De Luca, G. Cerboni, J.-D. Docquier, D.T. Davies, SAR studies leading to the identification of a novel series of metallo- $\beta$-lactamase inhibitors for the treatment of carbapenem-resistant enterobacteriaceae infections that display efficacy in an animal infection model, ACS Infect. Dis. 5 (2019) 131-140.

[37] Z.-J. Yu, S. Liu, S. Zhou, H. Li, F. Yang, L.-L. Yang, Y. Wu, L. Guo, G.-B. Li, Virtual target screening reveals rosmarinic acid and salvianolic acid A inhibiting metallo- and serine- $\beta$-lactamases, Bioorg. Med. Chem. Lett. 28 (2018) 1037-1042.

[38] N.J. Torelli, A. Akhtar, K. DeFrees, P. Jaishankar, O.A. Pemberton, X. Zhang, C. Johnson, A.R. Renslo, Y. Chen, Active-Site Druggability of Carbapenemases and Broad-Spectrum Inhibitor Discovery, ACS Infect. Dis. 5 (2019) 1013-1021.

[39] O.A. Pemberton, P. Jaishankar, A. Akhtar, J.L. Adams, L.N. Shaw, A.R. Renslo, Y. Chen, Heteroaryl Phosphonates as Noncovalent Inhibitors of Both Serine- and Metallocarbapenemases, J. Med. Chem. 62 (2019) 8480-8496.

[40] J. Brem, R. Cain, S. Cahill, M.A. McDonough, I.J. Clifton, J.-C. Jiménez-Castellanos, M.B. Avison, J. Spencer, C.W.G. Fishwick, C.J. Schofield, Structural basis of metallo- $\beta$-lactamase, serine- $\beta$-lactamase and penicillin-binding protein inhibition by cyclic boronates, Nat. Commun. 7 (2016) 1-8.

[41] S.T. Cahill, R. Cain, D.Y. Wang, C.T. Lohans, D.W. Wareham, H.P. Oswin, J. Mohammed, J. Spencer, C.W.G. Fishwick, M.A. McDonough, C.J. Schofield, J. Brem, Cyclic boronates inhibit all classes of $\beta$ lactamases, Antimicrob. Agents Chemother. 61 (2017) e02260-16.

[42] A. Krajnc, J. Brem, P. Hinchliffe, K. Calvopiña, T.D. Panduwawala, P.A. Lang, J.J.A.G. Kamps, J.M. Tyrrell, E. Widlake, B.G. Saward, T.R. Walsh, J. Spencer, C.J. Schofield, Bicyclic boronate VNRX-5133 inhibits metallo- and serine- $\beta$-lactamases, J. Med. Chem. 62 (2019) 8544-8556.

[43] A. Parkova, A. Lucic, A. Krajnc, J. Brem, K. Calvopiña, G.W. Langley, M.A. McDonough, P. Trapencieris, C.J. Schofield, Broad Spectrum $\beta$-Lactamase Inhibition by a Thioether Substituted Bicyclic Boronate, ACS Infect. Dis. 6 (2020) 1398-1404.

[44] Y.-L. Wang, S. Liu, Z.-J. Yu, Y. Lei, M.-Y. Huang, Y.-H. Yan, Q. Ma, Y. Zheng, H. Deng, Y. Sun, C. Wu, Y. Yu, Q. Chen, Z. Wang, Y. Wu, G.-B. Li, Structure-based development of (1-(3'mercaptopropanamido)methyl)boronic acid derived broad-spectrum, dual-action inhibitors of metallo- and serine- $\beta$-lactamases, J. Med. Chem. 62 (2019) 7160-7184.

[45] H. Staudinger, Zur Kenntniss der Ketene. Diphenylketen, Justus Liebigs Ann. Chem. 356 (1907) 51123.

[46] C.R. Pitts, T. Lectka, Chemical synthesis of $\beta$-lactams: asymmetric catalysis and other recent advances, Chem. Rev. 114 (2014) 7930-7953.

[47] K.A. DeKorver, H. Li, A.G. Lohse, R. Hayashi, Z. Lu, Y. Zhang, R.P. Hsung, Ynamides: A modern functional group for the new millennium, Chem. Rev. 110 (2010) 5064-5106.

[48] G. Evano, A. Coste, K. Jouvin, Ynamides: Versatile tools in organic synthesis, Angew. Chem. Int. Ed. 49 (2010) 2840-2859.

[49] P. Lu, Y. Wang, The thriving chemistry of ketenimines, Chem. Soc. Rev. 41 (2012) 5687-5705.

[50] R.H. Dodd, K. Cariou, Ketenimines Generated from Ynamides: Versatile Building Blocks for NitrogenContaining Scaffolds, Chem. - Eur. J. 24 (2018) 2297-2304.

[51] A. Hentz, P. Retailleau, V. Gandon, K. Cariou, R.H. Dodd, Transition-metal-free tunable chemoselective N-functionalization of indoles with ynamides, Angew. Chem. Int. Ed. 126 (2014) 8473-8477.

[52] E. Romero, C. Minard, M. Benchekroun, S. Ventre, P. Retailleau, R.H. Dodd, K. Cariou, Base-Mediated Generation of Ketenimines from Ynamides: Direct Access to Azetidinimines by an Imino-Staudinger Synthesis, Chem. - Eur. J. 23 (2017) 12991-12994.

[53] A. Van Camp, D. Goossens, M. Moya-Portuguez, J. Marchand-Brynaert, L. Ghosez, Synthesis of N(tosyl)azetidin-2-imines, Tetrahedron Lett. 21 (1980) 3081-3084. 
[54] M. Whiting, V.V. Fokin, Copper-Catalyzed Reaction Cascade: Direct Conversion of Alkynes into NSulfonylazetidin-2-imines, Angew. Chem. Int. Ed. 45 (2006) 3157-3161.

[55] T. Naas, S. Oueslati, R.A. Bonnin, M.L. Dabos, A. Zavala, L. Dortet, P. Retailleau, B.I. Iorga, Betalactamase database (BLDB) - structure and function, J. Enzyme Inhib. Med. Chem. 32 (2017) 917919.

[56] R.A. Bonnin, L. Poirel, A. Carattoli, P. Nordmann, Characterization of an IncFII plasmid encoding NDM-1 from Escherichia coli ST131, PLOS ONE. 7 (2012) e34752.

[57] M.L. Verdonk, J.C. Cole, M.J. Hartshorn, C.W. Murray, R.D. Taylor, Improved protein-ligand docking using GOLD, Proteins Struct. Funct. Bioinforma. 52 (2003) 609-623.

[58] M. Merino, F.J. Pérez-Llarena, F. Kerff, M. Poza, S. Mallo, S. Rumbo-Feal, A. Beceiro, C. Juan, A. Oliver, G. Bou, Role of changes in the L3 loop of the active site in the evolution of enzymatic activity of VIMtype metallo- $\beta$-lactamases, J. Antimicrob. Chemother. 65 (2010) 1950-1954.

[59] H.-K.S. Leiros, K.S.W. Edvardsen, G.E.K. Bjerga, Ø. Samuelsen, Structural and biochemical characterization of VIM-26 shows that Leu224 has implications for the substrate specificity of VIM metallo- $\beta$-lactamases, FEBS J. 282 (2015) 1031-1042.

[60] V.Studentova, C.C. Papagiannitsis, R. Izdebski, Y. Pfeifer, E. Chudackova, T. Bergerova, M. Gniadkowski, J. Hrabak, Detection of OXA-48-type carbapenemase-producing Enterobacteriaceae in diagnostic laboratories can be enhanced by addition of bicarbonates to cultivation media or reaction buffers, Folia Microbiol. (Praha). 60 (2015) 119-129.

[61] T. Che, C.R. Bethel, M. Pusztai-Carey, R.A. Bonomo, P.R. Carey, The Different Inhibition Mechanisms of OXA-1 and OXA-24 $\beta$-Lactamases Are Determined by the Stability of Active Site Carboxylated Lysine, J. Biol. Chem. 289 (2014) 6152-6164.

[62] C. Yung-Chi, W.H. Prusoff, Relationship between the inhibition constant (KI) and the concentration of inhibitor which causes 50 per cent inhibition (I50) of an enzymatic reaction, Biochem. Pharmacol. 22 (1973) 3099-3108.

[63] P. Artimo, M. Jonnalagedda, K. Arnold, D. Baratin, G. Csardi, E. de Castro, S. Duvaud, V. Flegel, A. Fortier, E. Gasteiger, A. Grosdidier, C. Hernandez, V. Ioannidis, D. Kuznetsov, R. Liechti, S. Moretti, K. Mostaguir, N. Redaschi, G. Rossier, I. Xenarios, H. Stockinger, ExPASy: SIB bioinformatics resource portal, Nucleic Acids Res. 40 (2012) W597-W603.

[64] C.R. Groom, F.H. Allen, The Cambridge Structural Database in Retrospect and Prospect, Angew. Chem. Int. Ed. 53 (2014) 662-671.

[65] E.F. Pettersen, T.D. Goddard, C.C. Huang, G.S. Couch, D.M. Greenblatt, E.C. Meng, T.E. Ferrin, UCSF Chimera-A visualization system for exploratory research and analysis, J. Comput. Chem. 25 (2004) 1605-1612.

[66] Y. Kim, M.A. Cunningham, J. Mire, C. Tesar, J. Sacchettini, A. Joachimiak, NDM-1, the ultimate promiscuous enzyme: substrate recognition and catalytic mechanism, FASEB J. 27 (2013) 19171927.

[67] W. Ke, C.R. Bethel, J.M. Thomson, R.A. Bonomo, F. van den Akker, Crystal Structure of KPC-2: Insights into Carbapenemase Activity in Class A $\beta$-Lactamases, Biochemistry. 46 (2007) 5732-5740.

[68] D.T. King, A.M. King, S.M. Lal, G.D. Wright, N.C.J. Strynadka, Molecular Mechanism of AvibactamMediated $\beta$-Lactamase Inhibition, ACS Infect. Dis. 1 (2015) 175-184.

[69] G. Surpateanu, B.I. Iorga, Evaluation of docking performance in a blinded virtual screening of fragment-like trypsin inhibitors, J. Comput. Aided Mol. Des. 26 (2012) 595-601.

[70] C. Colas, B.I. Iorga, Virtual screening of the SAMPL4 blinded HIV integrase inhibitors dataset, J. Comput. Aided Mol. Des. 28 (2014) 455-462.

[71] V.Y. Martiny, F. Martz, E. Selwa, B.I. Iorga, Blind Pose Prediction, Scoring, and Affinity Ranking of the CSAR 2014 Dataset, J. Chem. Inf. Model. 56 (2016) 996-1003.

[72] E. Selwa, V.Y. Martiny, B.I. Iorga, Molecular docking performance evaluated on the D3R Grand Challenge 2015 drug-like ligand datasets, J. Comput. Aided Mol. Des. 30 (2016) 829-839.

[73] E. Selwa, E. Elisée, A. Zavala, B.I. Iorga, Blinded evaluation of farnesoid X receptor (FXR) ligands binding using molecular docking and free energy calculations, J. Comput. Aided Mol. Des. 32 (2018) 273-286.

[74] L. Chaput, E. Selwa, E. Elisée, B.I. Iorga, Blinded evaluation of cathepsin S inhibitors from the D3RGC3 dataset using molecular docking and free energy calculations, J. Comput. Aided Mol. Des. 33 (2019) 93-103.

[75] E. Elisée, V. Gapsys, N. Mele, L. Chaput, E. Selwa, B.L. de Groot, B.I. Iorga, Performance evaluation of molecular docking and free energy calculations protocols using the D3R Grand Challenge 4 dataset, J. Comput. Aided Mol. Des. 33 (2019) 1031-1043. 
[76] R. Salimraj, P. Hinchliffe, M. Kosmopoulou, J.M. Tyrrell, J. Brem, S.S. van Berkel, A. Verma, R.J. Owens, M.A. McDonough, T.R. Walsh, C.J. Schofield, J. Spencer, Crystal structures of VIM-1 complexes explain active site heterogeneity in VIM-class metallo- $\beta$-lactamases, FEBS J. 286 (2019) 169-183. 